
\title{
BReserch S Suare \\ Opposite Peak Ratio to Characterize Ground Motion Loading History for Performance-Based Design
}

Arjun Jayaprakash ( $\nabla$ arjunjayaprakashm@gmail.com )

Karen Clark and Co https://orcid.org/0000-0002-4312-2724

Mervyn J. Kowalsky

North Carolina State University

\section{Research Article}

Keywords: Opposite peak ratio, Displacement-based design, RC bridge columns, Non-linear dynamic analyses

Posted Date: May 10th, 2021

DOI: https://doi.org/10.21203/rs.3.rs-487857/v1

License: (1) This work is licensed under a Creative Commons Attribution 4.0 International License. Read Full License 


\section{Opposite Peak Ratio to Characterize Ground Motion Loading History for Performance-Based Design}

Arjun Jayaprakash $^{1}$, M. J. Kowalsky ${ }^{2}$

(1) Senior Earthquake Engineer, Karen Clark and Company, Boston, MA. Email id: arjunjayaprakashm@gmail.com

(2) Professor, Department of Civil, Construction, and Environmental Engineering, North Carolina State University Raleigh, NC, USA. Email id: kowalsky@ncsu.edu 


\begin{abstract}
Recent studies have revealed the impact of ground motion loading history on performance limit states of reinforced concrete (RC) bridge columns such as reinforcement bar-buckling and residual drift ratio. Conventional hazard characterizations such as peak ground acceleration, spectral acceleration, and spectral displacement only capture peak values of ground motion hazard and, therefore, fall short of providing the necessary information to account for these limit states. In this study, a parameter termed as the opposite peak ratio $\left(\mathrm{R}_{\mathrm{op}}\right)$ is defined, explored, and shown to be useful in reproducing loading history characteristics of ground motions for displacement-based design. Several past ground motion records were analyzed to develop empirical models that can estimate $R_{\text {op }}$. These models provide the mean and confidence intervals of $R_{\mathrm{op}}$ as a function of earthquake magnitude, epicentral distance, structural period, hysteretic model, and displacement ductility. To motivate practitioners to make use of $\mathrm{R}_{\mathrm{op}}$, a design scenario and two case studies are discussed. In an RC bridge column design scenario, it is shown that having prior information about the expected $R_{o p}$ at the site could reduce the structural cost of the bridge. Next, case studies designed to investigate correlations between $\mathrm{R}_{\mathrm{op}}$ and the performance limit states of $\mathrm{RC}$ bridge columns are discussed. By analyzing the results of nonlinear time-history analyses of numerical RC column models, it is established that $\mathrm{R}_{\mathrm{op}}$ could potentially be a significant variable in generating fragility models for these limit-states.
\end{abstract}

analyses

Keywords: Opposite peak ratio, Displacement-based design, RC bridge columns, Non-linear dynamic

\title{
1. Introduction
}

The main goal of performance-based seismic design (PBSD) philosophy (Moehle and Deierlein, 2004) is the accurate prediction of structural performance, and in turn, damages and losses incurred by a structure under different earthquake hazard levels to facilitate informed decision making. A structural design philosophy that can be seamlessly incorporated into PBSD is the direct displacement based design (DDBD), presented in Priestley et al. (2007). In DDBD, hazard characterizations are combined with structural performance limit state models for designing a structure to achieve the desired level of structural performance under varying levels of seismic input. Typically, limit state models are either empirical or semi-empirical relationships between engineering demand parameters and performance limit states of structural members. For example, it is possible to ascertain if a structural member has passed the yield point if the section curvature is known (Priestley et al., 2007). Likewise, expressions exist to estimate rebar strains at which longitudinal reinforcement bar-buckling occurs in reinforced concrete (RC) columns (Goodnight et al., 2016). These models allow engineers to design a structure to desired outcomes based on the expected seismic demand. The seismic demand is usually evaluated using hazard maps or models that provide numerical characterizations of potential seismic events. A popular method of hazard characterization is by using intensity measures (IM). The most common IMs in current use are peak ground acceleration (PGA), peak spectral acceleration $\left(\mathrm{S}_{\mathrm{a}}\right)$, and peak spectral displacement $\left(\mathrm{S}_{\mathrm{d}}\right)$. These IMs capture the peak response of elastic single-degree-of-freedom (SDOF) structures under any given ground motion.

However, ground motions are more complicated than what can be conveyed through peak parameters (Malhotra, 2002). Many performance limit-states, especially those related to local structural damage, are often more influenced by characteristics of the ground motion loading history that are different from peak parameters (Goodnight et al., 2013). The loading history of a ground motion refers to the full time-series description of the structure's response to a ground motion input. Because characteristics of one seismic event may never be repeated, engineers have resorted to characterizing a few essential aspects of the loading history that have a significant impact on structural damage. These aspects include but are not limited to, the duration, frequency content, cyclic sequence type, number of significant cycles, and unbalanced nature of seismic ground motions.

The impact of ground motion loading history on the behavior of different structural elements has been well documented (Teran-Gilmore and Jirsa, 2005; Kalkan and Kunnath, 2006; Pujol et al., 2006; Iervolino et al., 2006; Syntzirma et al., 2009; Raghunandan and Liel, 2013; Goodnight et al., 2013; Feng et al., 2014a). There has also been a wealth of studies that provide various quantifiable measures to characterize the loading history of ground motions (Bolt, 1973; Fajfar, 1992; Malhotra, 2002; Bommer et al., 2006; Kalkan and Kunnath, 2007; Du and Wang, 2017). However, the usefulness of each such characterization is predicated on the type of limit state model used by a structural 
designer. There is no single measure that can be applied universally. For example, the Feng et al. (2014a) model for $\mathrm{RC}$ columns accounts for the impact of loading history by capturing the damage incurred due to the out-of-balance structural response under cyclic loading. The out-of-balance response refers to the unequal peak displacement of structures to either side of their initial position, during a ground motion input. For any ground motion parameter to be useful for this damage model, it must be able to provide information regarding this out-of-balance nature of the structural response.

In this paper, a parameter is proposed that can capture the out-of-balance nature of structural response histories and provide valuable input for limit state models in DDBD. This parameter is termed as the opposite peak ratio $\left(\mathrm{R}_{\mathrm{op}}\right)$. The objectives of this paper are to introduce the opposite peak ratio, develop empirical models that can estimate the opposite peak ratio for a given set of ground motion parameters, and illustrate the implications of estimating $R_{\mathrm{op}}$ through three different example scenarios. Before discussing the opposite peak ratio in detail, the background on load history characterization of ground motions is summarized.

\section{Load History Characterization of Ground Motions}

When posing the expected hazard for DDBD, it is vital to supply the designer with as much information as possible. Because of the erratic nature of earthquakes, however, it is near impossible to predict the full time-series data of a future ground motion event. Conventionally, the approach to solving this problem has been to supplement the designer with additional parameters that capture some significant aspects of ground motion, not contained in peak parameters. For example, Fajfar (1992) realized that the level of structural damage due to earthquakes not only depends on maximum displacement but also cumulative damage resulting from numerous inelastic cycles. He added that aspects of the whole inelastic displacement time-history, i.e., the number, sequence, and relative amplitude of inelastic excursions, have a significant impact on cumulative damage. At the time, it was not easy to consider the details of a response time-history. However, there have been multiple studies since then that have attempted to characterize ground motion loading history.

The duration of the ground motion is one of the earliest parameters that capture the effects of loading history. Longer duration of ground shaking tends to impart a larger amount of energy to a structure. Energy-based damage parameters are, therefore, sensitive to ground motion duration. Including early contributions from Housner (1965), Husid (1967), Bolt (1973), and Trifunac and Brady (1975), more than 20 different definitions of ground motion duration have been proposed over the years. The influence of duration on structural damage is still a topic of some debate. While some studies have found that the influence of duration on structural capacity is insignificant (Iervolino et al., 2006; Hancock and Bommer, 2007; Raghunandan and Liel, 2013), other studies show capacity depletion of a few specific structures under larger duration ground motions (Chandramohan et al., 2016; Pan et al., 2018).

The equivalent ductility factor $\gamma$, introduced by Fajfar (1992) and Fajfar and Vidic (1994) accounts for the reduction in the ductility capacity of structures due to many cyclic load reversals during ground motions. The utility of $\gamma$ was within the framework of force-based design in modifying the force reduction factor (R) to account for lowcycle fatigue, which is the inability of a structure to attain as much ductility capacity under cyclic load reversals as predicted by the conventional monotonic analysis.

Cumulative cyclic demand spectrum, introduced by Malhotra (2002), captures the effect of the number of loading cycles on the depletion of strength, stiffness, and energy dissipation capacity of a structure. Kunnath and Chai (2004) extended this work and provided an analytical definition of a parameter called the equivalent number of cycles of structural response. The equivalent number of cycles can be derived from the energy dissipated by a structure during a ground motion by assuming a particular hysteretic model.

The effective cyclic energy (ECE) was proposed by Kalkan and Kunnath (2007) as an improved demand measure for energy-based seismic design approaches. They noted that most of the damage caused by near-fault records is a result of instantaneous energy demands associated with intense pulse effects. In this case, low-cycle fatigue effects are less pronounced, and structural damage is directly related to peak seismic demands. ECE thus mitigated apparent discrepancies in previous energy demand measures due to directivity effects. By characterizing the energy demand of 
ground motion, this parameter effectively captures some aspects of loading history. ECE also correlated better with the maximum displacement of SDOF systems when compared to other demand measures.

Overall, all of the useful characterizations listed above were addressing issues at a global scale of structural degradation and have evolved from the purview of either force-based or energy-based seismic design philosophies. Moreover, the loading history aspect captured by these parameters is the energy demand and the cyclic nature of ground motions. DDBD, however, relies on global displacement limit states derived from accurate descriptions of local damage phenomena. Limit state models for DDBD are improved continuously, and to be able to utilize these models efficiently, it is imperative to improve older or develop newer demand measures. This paper proposes a simple parameter called the opposite peak ratio $\left(\mathrm{R}_{\mathrm{op}}\right)$ that can be used in DDBD to account for the out-of-balance nature of the structural response to ground motions. This parameter is introduced in the next section.

The ultimate research goal, for which this study is only the first step, is to develop a suite of parameters that can be deployed during the DDBD process to reasonably capture hazardous aspects of ground motion loading history. This suite must inevitably include parameters that can capture the significant duration, number of significant inelastic cycles, the out-of-balance nature of the structural response, and others that may emerge in the future.

\section{The Opposite Peak Ratio}

For a single degree of freedom (SDOF) oscillator with mass $m$ and an associated damping coefficient $c$, the equation of motion for a uni-directional seismic input is given by Equation 1, where $\dot{u}$, and $\ddot{u}$ are time derivatives of the displacement $u, f_{s}(u)$ is the non-linear relationship between displacement and resisting forces (for linear SDOF, $f_{s}(u)=k u$, where $k$ is the stiffness), and $\ddot{u}_{g}$ is the time varying ground acceleration. The solution to this second order differential equation is the time dependent relative displacement of the oscillator, $u(t)$. The opposite peak ratio $\left(R_{o p}\right)$ is defined as the absolute value of the ratio of the peak displacements on either side of the initial position of a SDOF oscillator under a ground motion input, evaluated as described in Equation 2. In this equation, $u_{\max }(t)$ and $u_{\min }(t)$ are the maximum and minimum values of the displacement response, $u(t)$.

It is convenient to place the smaller absolute value of the two displacements on the numerator to limit $R_{o p}$ between 0.0 and 1.0, hence the discontinuous nature of the function. The closer $R_{o p}$ is to unity, the more balanced is the displacement response. Fig 1 is a sample displacement response history of an inelastic SDOF oscillator under a real ground motion. When evaluated, $R_{o p}$ for this particular response was 0.29 . This example suggests the possibility of observing a significant imbalance between displacements on either side of the oscillator.

$$
\begin{aligned}
& m \ddot{u}+c \dot{u}+f_{s}(u)=-m \ddot{u_{g}}(t) \\
& R_{o p}= \begin{cases}\left|\frac{u_{\min }(t)}{u_{\max }(t)}\right|, & \text { if } u_{\min }(t)+u_{\max }(t)>0 \\
\left|\frac{u_{\max }(t)}{u_{\min }(t)}\right|, & \text { if } u_{\min }(t)+u_{\max }(t)<0\end{cases}
\end{aligned}
$$

The opposite peak ratio was explored both in the elastic and inelastic domains of structural response. The motivation for investigating $R_{o p}$ had risen initially from the need to estimate limit states in the domain of inelastic response. Therefore, this paper's primary focus, including the scenarios discussed later, pertains to structural limit states occurring during the inelastic response. However, a choice was made to first investigate $R_{o p}$ under the elastic response of SDOF oscillators. There were a few important considerations that led to this choice. First was that elastic analysis, being much simpler and faster than non-linear dynamic analysis, enabled studying a much higher number of ground motions and associated $R_{o p}$ values. Thus, higher confidence could be placed in the observed trends. Second, seismic hazards are conventionally posed in the form of the elastic response of SDOF oscillators. Thus, estimating an elastic $R_{o p}$ could supplement the existing information regarding peak parameters. For example, a typical response spectrum, when multiplied by the appropriate $R_{o p}$, could provide the information regarding the opposite peak. And lastly, while only two structural limit-states are discussed in this paper as being influenced by $R_{o p}$, it was recognized 
that there could also be other unbeknownst damage phenomena that occur within the elastic response domain, which may be affected by $R_{o p}$.

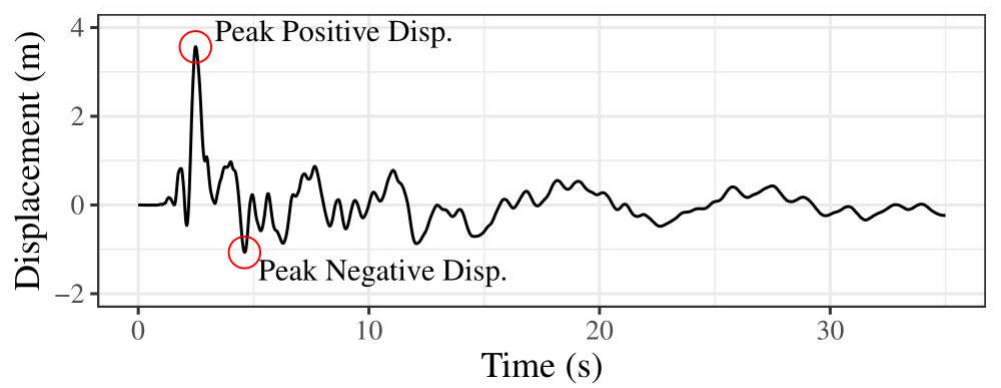

Fig 1. Sample displacement response history of a non-linear SDOF oscillator with positive and negative peaks annotated.

\section{Opposite Peak Ratio for Elastic Response - Elastic $\boldsymbol{R}_{o p}$}

\subsection{Method}

An extensive suite of earthquake ground motion records (1554 records) was obtained from the PEER NGA-West2 database (Ancheta et al., 2014). The ground motions were chosen so that the dataset consisted of records from a wide range of magnitudes $\left(M_{W}\right)$ and closest distance parameters $(D)$. All 1554 ground motion records were then analyzed to obtain the elastic $R_{o p}$ for each one of them for SDOF periods between $0.1 \mathrm{~s}$ to $10.0 \mathrm{~s}$. Fig 2 shows scatterplots of $M_{W}$ and $D$ pairs of all records in both the datasets.

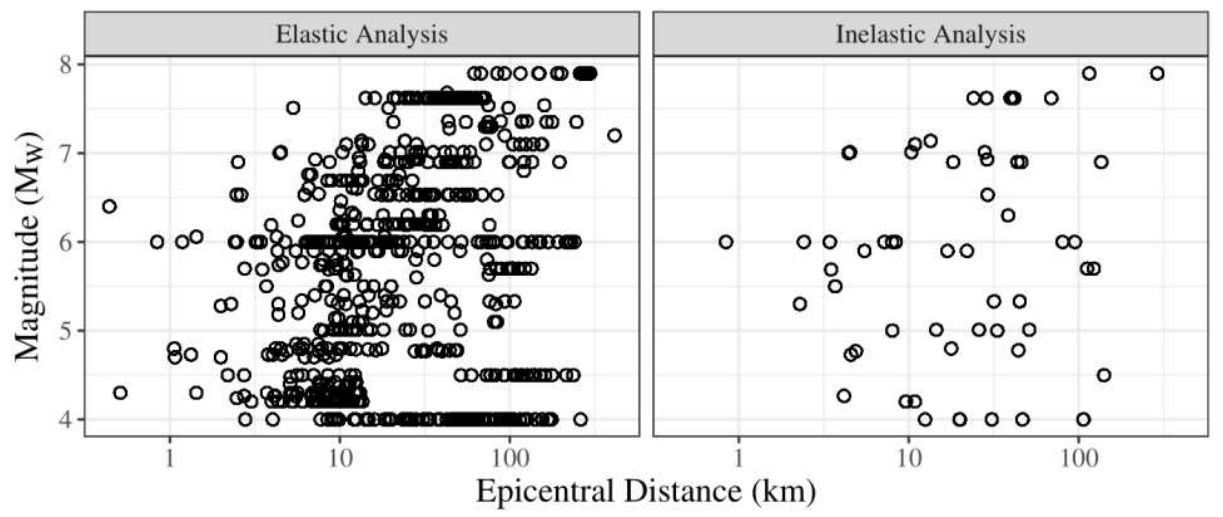

Fig 2. Moment magnitude versus epicentral distance for the two GM datasets used in this study.

An exploratory data analysis discussed elsewhere (Jayaprakash and Kowalsky, 2019) was performed by random sampling to investigate the impact of multiple variables on $R_{o p}$. It was found that the variables having the most correlation with elastic $R_{o p}$ were the initial period $(T)$, event magnitude $(M)$, and the distance $(D)$ to the epicenter.

A statistical method known as bootstrap (Friedman et al., 2001) was employed to obtain expressions for predicting the mean $\left(\mu_{o p}\right)$ and the $95^{\text {th }}$ percentile confidence interval ( $\left.\mu_{o p \pm 95}\right)$ of the mean of $R_{o p}$. Bootstrap is a statistical resampling technique that can be used to estimate a parameter and confidence interval from a single sample in lieu of making parametric assumptions about the estimator's sampling distribution. For example, if a parameter from an unknown population must be estimated from a single sample of a certain sample size, thousands of repeated samples can be obtained from the sample with replacement. This re-sampling can be simulated in any statistical software. A confidence interval can be constructed for the mean value of an estimator by finding the sample means and standard 
deviations of the means for all of the samples. Fig 3 shows a schematic illustrating the typical steps in bootstrap resampling. In this study, the estimated parameter was $R_{o p}$.

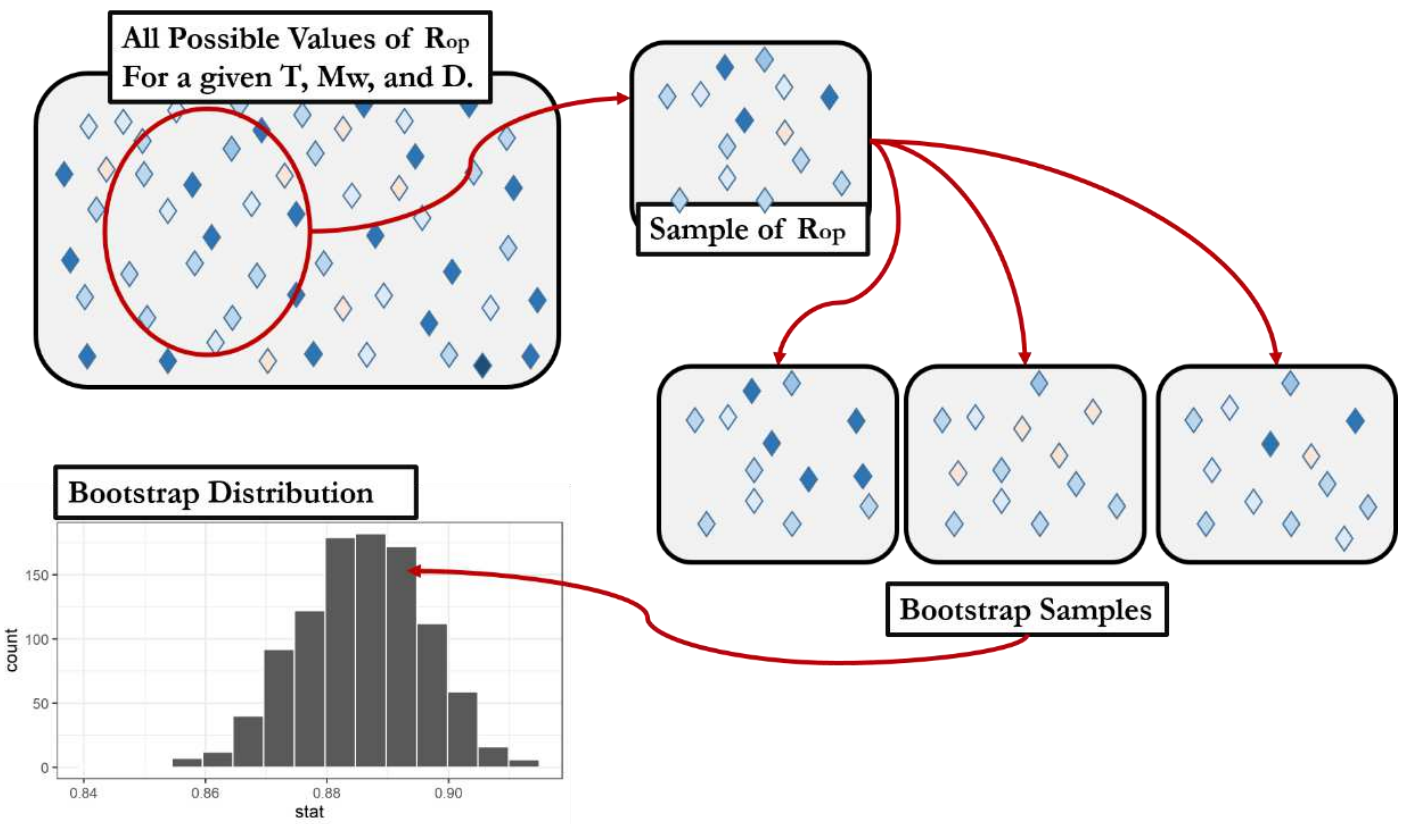

Fig 3. A schematic visualizing typical steps of bootstrapping a probability distribution for a parameter.

Realizations of $R_{o p}$ within pre-defined period-magnitude-distance joint bins were used as default samples for bootstrapping. There were eight different distance bins classified based on the site's epicentral distance. These were "0 to $5 \mathrm{~km}$ ", "5 to $10 \mathrm{~km}$ ", "10 to $15 \mathrm{~km}$ ", "15 to $25 \mathrm{~km}$ ", " 25 to $40 \mathrm{~km}$ ", "40 to $60 \mathrm{~km}$ ", "60 to $90 \mathrm{~km}$ ", and "Greater than $90 \mathrm{~km}$ ". The magnitudes were divided into two bins grouped based on the correlation with $R_{o p}$. The observations were classified into magnitude bins based on whether the events had moment magnitudes "Below 7.0 or " 7.0 or above". This choice was made based on the impact of the grouping on $R_{o p}$, determined by trial and error. The periods used were between $0.5 \mathrm{~s}$ and $10.0 \mathrm{~s}$ at increments of $0.5 \mathrm{~s}$. Thus, to generate a default sample for bootstrapping, all values of $R_{o p}$ that fell within any given joint bin were extracted and grouped.

A total of 2000 bootstrap samples was obtained for each default sample. Then, the mean opposite peak ratio $\left(\mu_{o p}\right)$ and its confidence interval $\mu_{o p \pm 95}$ were calculated for each default sample. The resulting data was then used to fit linear regression models to estimate $\mu_{o p}$.

\subsection{Results}

An empirical model was developed to estimate the elastic $R_{o p}$. Fig 4 shows the result of bootstrapping for observations from ground motion records with epicentral distances between $0 \mathrm{~km}$ to $40 \mathrm{~km}$, collectively termed as near-fault records. Note that this terminology is arbitrary and only for the purpose of nomenclature. No relationship need be drawn between this term and its namesake used by seismologists (near-fault or near-field). The data-points in this figure are empirically bootstrapped mean values of the opposite peak ratio $\left(\mu_{o p}\right)$. A linear model was fit to obtain the mean and $95^{t h}$-percentile two-sided confidence interval of $\mu_{o p}$. This model is also dependent on the moment magnitude $\left(M_{W}\right)$ of the earthquake. $\mu_{o p}$ for all earthquakes having $M_{W}$ below 7.0 showed a clear linear trend. For $M_{W}$ at or above 7.0, there was more scatter and deviation from linearity. While a linear fit is still used for the mean, it is recommended that the $95^{\text {th }}$-percentile confidence interval is used for large-magnitude events. 


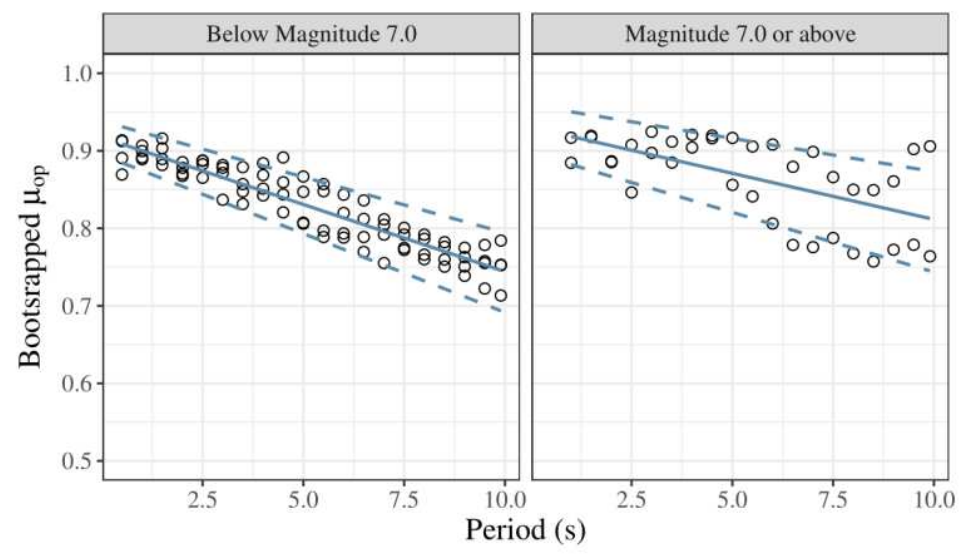

Fig 4. Bootstrapped mean values of elastic $R_{o p}$ for ground motions recorded at locations less than $40 \mathrm{~km}$ from the epicenter alongside the fitted models for the mean (solid) and its $95^{\text {th }}$-percentile two-sided confidence interval (dashed).

All ground motion records with epicentral distances above $40 \mathrm{~km}$ were classified together as one category, while those below $40 \mathrm{~km}$ were considered separately. This separation point of $40 \mathrm{~km}$ was based on the observed correlations. It was observed that the out-of-balance nature of the response was less pronounced for records with a distance of above $40 \mathrm{~km}$. The slope of the linear model for these records was shallower compared to records with distance below $40 \mathrm{~km}$. The variation of $\mu_{o p}$ with changes in magnitude was also minor for records with epicentral distance above $40 \mathrm{~km}$.

Equation 3(a,b,c) provides the empirical model to estimate $\mu_{o p}$ for elastic response of SDOF structures. In these equations, $\hat{R}_{o p}$ is a generic notation used for an estimator of the opposite peak ratio. Three estimators were considered in this study, viz., the mean value of the mean opposite peak ratio $\left(\mu_{o p}\right)$, the upper bound $\left(\mu_{o p 95+}\right)$ and the lower bound $\left(\mu_{o p 95-}\right)$ of the $95^{t h}$-percentile confidence interval for $\mu_{o p}$. By varying the coefficients $\left(\beta_{0}, \beta_{1}, \beta_{2}\right.$, and $\left.\beta_{3}\right)$ of the model based on the values provided in Table 1, envelopes for possible values of $\mu_{o p}$ can be generated for a new design.

$$
\begin{gathered}
\hat{R}_{o p}=\beta_{0}+\beta_{1} T+\beta_{2} M_{f}+\beta_{3} D_{f} \\
M_{f}= \begin{cases}0, & \text { if } M_{w}<7.0 \\
1, & \text { if } M_{w} \geq 7.0\end{cases} \\
D_{f}= \begin{cases}0, & \text { if } D \leq 40 \mathrm{~km} \\
1, & \text { if } D>40 \mathrm{~km}\end{cases}
\end{gathered}
$$

Table 1. Coefficients for the model given by Equation 3 to estimate $R_{o p}$ for elastic response.

\begin{tabular}{|c|c|c|c|c|}
\hline Estimator $\left(\widehat{R}_{o p}\right)$ & $\beta_{0}$ & $\beta_{1}$ & $\beta_{2}$ & $\beta_{3}$ \\
\hline$\mu_{o p}$ & 0.88 & -0.010 & 0.030 & 0.040 \\
\hline$\mu_{o p 95+}$ & 0.91 & -0.008 & 0.025 & 0.025 \\
\hline$\mu_{o p 95-}$ & 0.84 & -0.011 & 0.035 & 0.056 \\
\hline
\end{tabular}

To validate this model, first, 2000 observations were randomly sampled from a partial elastic response database 500 times. This partial database was separated from the initial set for the purpose of validation and was not used in the development of the model. The number of samples was shown to be large enough to produce convergent outcomes in Jayaprakash and Kowalsky (2019). Then, the $R_{o p}$ was averaged over each period, magnitude and epicentral distance bins to obtain $\mu_{o p}$, which was plot versus period, as shown in Fig 5. This figure shows the results for the "near-fault" records. The linear models for mean and confidence intervals of $\mu_{o p}$ were then superimposed on the plot to ensure that the prediction is reasonable. While earthquakes with magnitudes below 7.0 show an apparent linear reduction in $\mu_{o p}$ with an increasing period, larger magnitude earthquakes (above 7.0) show erratic behavior. However, the 
confidence bounds reasonably capture the range of possible values of $\mu_{o p}$. From the case-studies discussed later, it can be seen that estimation of the bounds (upper and lower) provides sufficient information for improving the design.

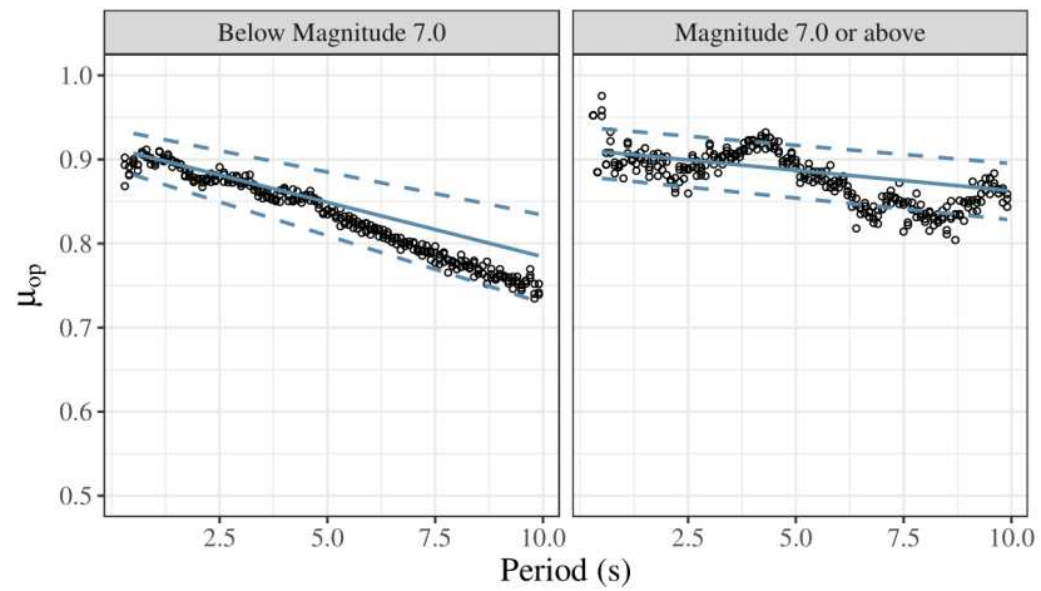

Fig 5. Mean opposite peak ratios $\left(\mu_{o p}\right)$ for near-fault records from 500 random samples of size 2000 obtained from the validation database alongside the fitted models for the mean (solid) and its $95^{\text {th }}$-percentile two-sided confidence interval (dashed).

\section{Opposite Peak Ratio for Inelastic Response - Inelastic $\boldsymbol{R}_{o p}$}

5.1 Method

NLTH analyses were performed on SDOF systems with periods ranging from 0.25 s to 10.0 s utilizing a smaller subset of 120 ground motion records. This reduction in the total number of records used for the analyses involving inelastic systems was necessary because the hysteretic response type is now included as a new explanatory variable with five different realizations. Sticking to the original number of downloaded records would have expanded the total number of required analyses to be intractable. These 120 records were randomly sampled from the available set of 1554 ground motions used for elastic analysis. Distribution of magnitude and epicentral distance of these recorded ground motions are shown in Fig 2. The sample set still covers the full range of magnitude and epicentral displacements covered for the elastic case.

A one component Giberson beam member (Sharpe, 1974) was used to model the SDOF systems. Five different section hysteresis models, namely, Bilinear, Ramberg-Osgood (Ramberg and Osgood, 1943), thin and large versions of the modified Takeda (Otani, 1980), and Flag-shaped (Carr, 2008) were used to represent a range of structural systems (Fig 6). Parametric details for each model are presented in Table 2. For a meaningful comparison of responses among different hysteretic models, the section yield moment of the SDOF systems was kept the same, effectively normalizing the results. Analyses were repeated for two different yield moments $1000 \mathrm{kNm}$ and $2000 \mathrm{kNm}$, to produce responses at different ductility levels. Tangent stiffness proportional Rayleigh damping with secant damping variation (Carr, 2008) was used for all of the analyses with 5\% damping ratio in the first and second modes of SDOF response.

Over 15000 non-linear dynamic analyses were performed using the dynamic analysis software Ruaumoko (Carr, 2008). Newmark's constant average acceleration integration scheme (Humar, 2012) was implemented using the householder QR eigenvalue algorithm. The time-step of integration was chosen to be the same as the time interval of the respective ground motion record. $R_{o p}$ was then calculated from the displacement response history of each analysis.

In the exploratory data analysis (Jayaprakash and Kowalsky, 2019), the variables exhibiting good correlation with inelastic $R_{o p}$ were the period, maximum ductility, and the hysteresis model of the SDOF oscillator. For inelastic $R_{o p}$, multiple linear regression was used to obtain an expression for the logarithmic transformation of the opposite peak ratio $\left(\log _{10}\left(\mu_{o p}\right)\right)$ of SDOF systems as a function of its target ductility $\left(\mu_{\Delta}\right)$ and hysteretic model. 

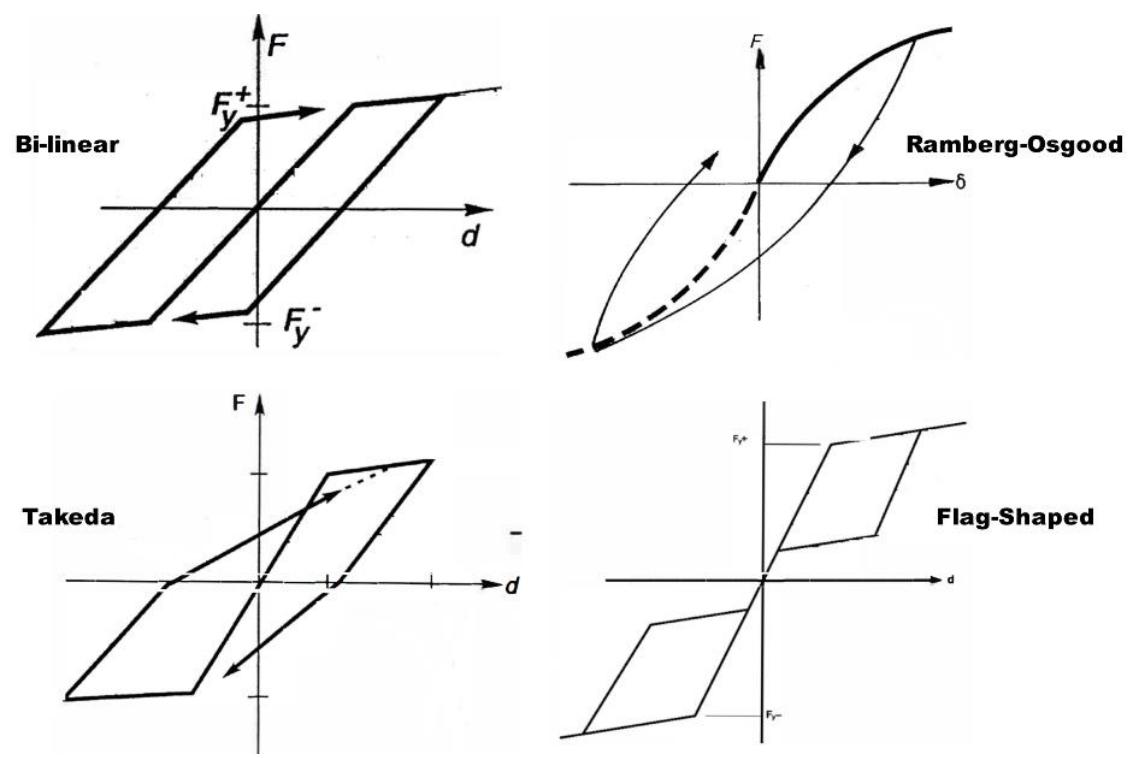

Fig 6. Typical force-displacement cycles for the section hysteresis models used for non-linear time history analysis of SDOF systems to obtain $R_{o p}$.

Table 2. Details of different hysteretic models utilized for NLTH analyses of SDOF systems in Ruaumoko-3D.

\begin{tabular}{|c|c|c|c|c|c|}
\hline Parameter & Bi-linear & Ramberg-Osgood & Thin-Takeda & Large-Takeda & Flag-shaped \\
\hline $\begin{array}{c}\text { Bi-linear factor } \\
(r)\end{array}$ & 0.01 & - & 0.01 & 0.01 & 0.01 \\
\hline $\begin{array}{c}\text { Ramberg- } \\
\text { Osgood factor } \\
\left(r^{\prime}\right)\end{array}$ & - & 5 & - & - & - \\
\hline $\begin{array}{c}\text { Takeda } \\
\text { unloading } \\
\text { stiffness }\left(\alpha_{t}\right)\end{array}$ & - & - & 0.05 & 0.0 & - \\
\hline $\begin{array}{c}\text { Takeda } \\
\text { reloading } \\
\text { stiffness }\left(\beta_{t}\right)\end{array}$ & - & - & 0.0 & 0.6 & - \\
\hline Flag-size $\left(\beta_{f}\right)$ & - & - & - & - & 0.8 \\
\hline
\end{tabular}

\subsection{Results}

The model for inelastic $R_{o p}$ accounts for the impact of the nonlinear hysteretic model and ductility of the SDOF structure, as described by DDBD principles. The hysteretic model used to perform dynamic analyses had a significant impact on the SDOF response's out-of-balance nature. While this result was expected qualitatively, it was now possible to quantify the different behavior of the type of non-linearity considered with regards to their out-of-balance response to ground motions. Fig 7 shows boxplots of observed $R_{o p}$ values for each hysteretic model. The median $R_{o p}$ for each model is annotated on the figure, from which the variation in $R_{o p}$ can be distinctly observed. The modified Takeda (thin and large) model, which simulates reinforced concrete structures, has a larger out-of-balance response than the Ramberg-Osgood model, which represents steel structures. Self-centering systems, represented by the flag-shaped model, show the largest $R_{o p}$ indicating the least out-of-balance in their response. This observation is not surprising since self-centering systems characterized by such a hysteretic response exhibit reduced ratcheting. Similarly, the bilinear hysteretic model, which is prone to the highest amount of ratcheting, exhibits the least $R_{o p}$. 
After performing statistical analysis of the dataset for non-linear SDOF oscillators, the best model that can estimate the inelastic $R_{o p}$ was selected. This model is given by Equation $4(\mathrm{a}, \mathrm{b}, \mathrm{c}, \mathrm{d})$ where $\mu_{\Delta}$ is the ductility at which any structure is intended to achieve a given performance limit-state, $T_{e f f}$ is the effective period of the structure corresponding to the same limit-state, $\epsilon$ is the standard error of the predicted parameter, $\log _{10}\left(\mu_{o p}\right)$, and $\sigma$ is the standard deviation. The variables $\mu_{\Delta}$ and $T_{\text {eff }}$ are considered as explanatory variables because they are known upfront in the design process to a designer following DDBD principles.

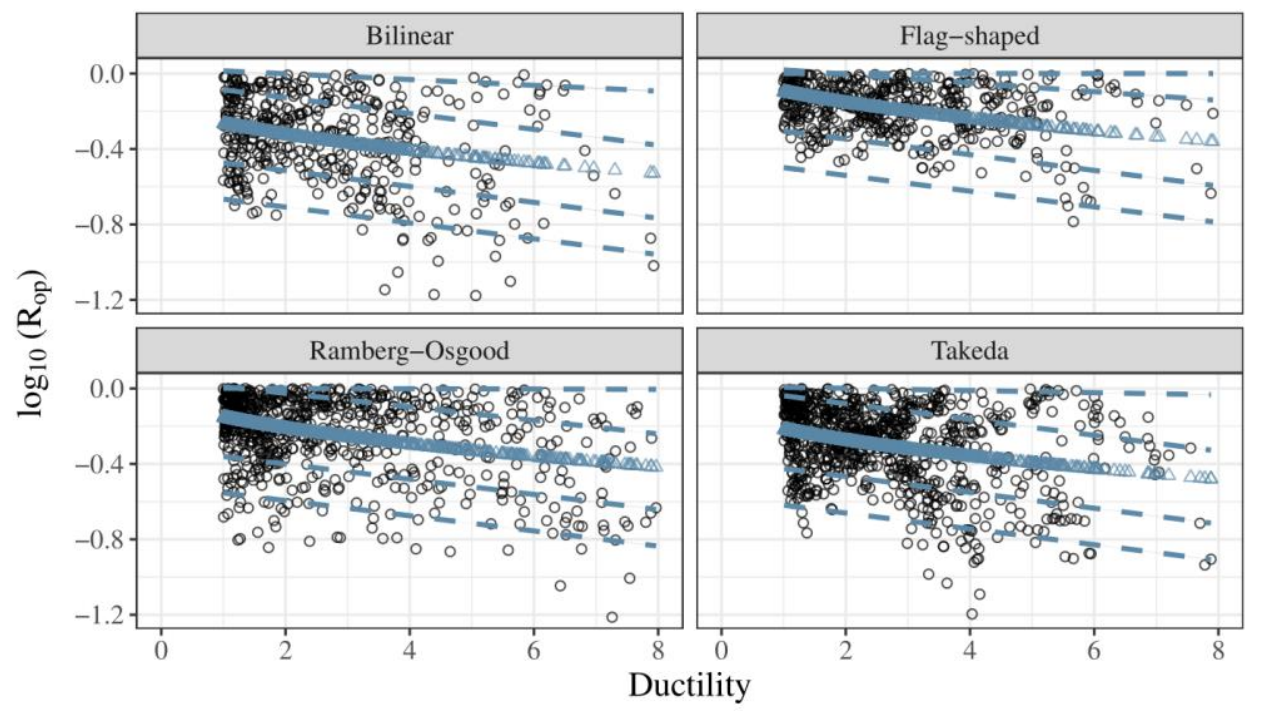

Fig 8. Non-linear $\log _{10}\left(R_{o p}\right)$ plotted against the SDOF ductility for each hysteretic model.

$$
\begin{gathered}
\log _{10}\left(\mu_{o p}\right)=-\left(0.15 \sqrt{\mu_{\Delta}}+\beta_{h}\right)+\epsilon \\
\beta_{h}=\left\{\begin{array}{cr}
0.12, & \text { for Bi-linear } \\
0.072, & \text { for Takeda } \\
0.007, & \text { for Ramberg }- \text { Osgood } \\
-0.048, & \text { for Flag }- \text { shaped }
\end{array}\right. \\
\epsilon=0.007 \\
\sigma=0.19
\end{gathered}
$$

The validation method for inelastic $R_{o p}$ was the same as that used for elastic $R_{o p}$. One hundred random samples with 2000 observations were sampled from the inelastic dataset set aside for validation. $\log _{10}\left(\mu_{o p}\right)$ for all of the observations were then plotted against SDOF ductility. Predicted values of $\log _{10}\left(\mu_{o p}\right)$ were then superimposed on the real data to ascertain the accuracy visually. Fig 8 shows this plot in which real data is plotted as black circles and predicted data as blue triangles. Each blue dashed line indicates an increment of one standard deviation $(\sigma)$ above and below the predicted values. It was observed that the real data is spread around the predicted values. Furthermore, the bounds created by two standard deviations above and below the predicted values capture the range of possible values of $\log _{10}\left(\mu_{o p}\right)$.

It is important to note that these models can only be applied within the range of variables chosen for this study. All of the ground motions used in this study were from shallow-crustal earthquake events. The moment-magnitudes of these events ranged between 4.0 and 7.9. However, the number of records from large magnitude events, such as above 7.0, 
were smaller than lower magnitude events. Likewise, the epicentral distances of a significant portion of the dataset were between $0 \mathrm{~km}$ and $70 \mathrm{~km}$. The hysteresis models used for NLTH analysis of SDOF oscillators were all normalized to the same yield strength and a bi-linear factor $(r)$ of 0.01 .

\section{Current Implications of Estimating the Opposite Peak Ratio}

The remainder of this paper examines how $R_{o p}$ can become a useful parameter for engineers in performing both design and assessment. Empirical models that were developed in this study for $R_{o p}$ estimation can be immediately useful in DDBD. In this section, an engineering scenario is presented to illustrate the significance of $R_{o p}$. Two case-studies depicting potential applications of $R_{o p}$ are presented in the subsequent section.

\subsection{DDBD of Bridge Columns for the Bar-Buckling Limit State}

Consider a sample RC bridge structure, as shown in Fig 9. In this structure, the columns in each of the two piers must act as the primary energy dissipating members during earthquakes. In this case, these columns are pin-supported and therefore act in single bending under transverse loading. Under this load, buckling of the extreme longitudinal bars of columns just below the cap beam becomes an important limit-state because the structural system loses significant strength thereafter.

To account for this limit-state, Priestley et al. (2007) recommends the use of strain-based performance limit states for establishing the target displacement and, in turn, enforcing a limit on the strain in reinforcing steel under the expected demand. The strain limit for bar-buckling under cyclic loading is significantly lower than that under monotonic loading because of the rebar strain switching between tension and compression (Moyer and Kowalsky, 2003). Moreover, in a seismic event, this limit also depends on the history of cyclic loading (Syntzirma et al., 2009; Goodnight et al., 2013). These observations mean that reinforcement bar-buckling depends on two things: the relative displacement of a column on either side of its initial position (Feng et al., 2014a, b) and the number of cycles at different inelastic levels (Bazaez and Dusicka, 2016). To account for seismic loading history in the prediction of reinforcement bar-buckling, Feng et al. (2014a) proposed an empirical model that considers the interaction between the tension and compression strain histories of a single rebar.

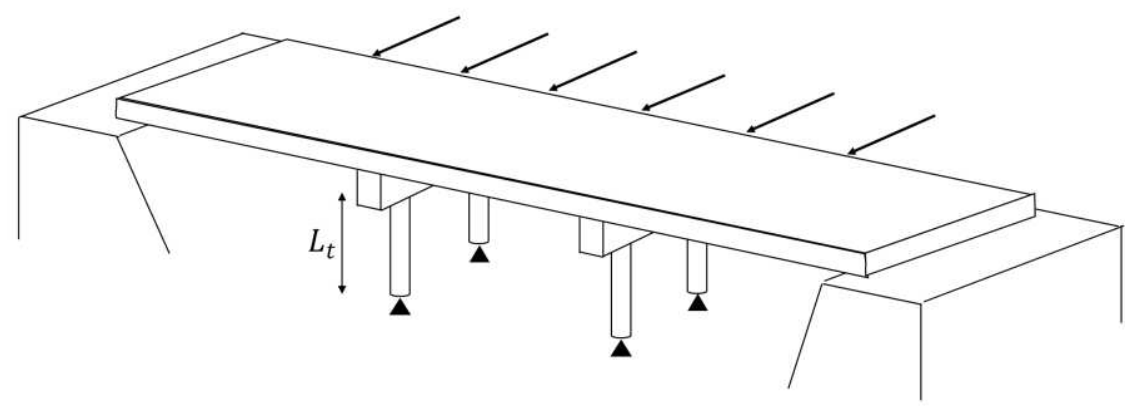

Fig 9. A sample bridge structure.

For designing the bridge columns in Fig 9 for loading in the transverse direction, the first step is to evaluate a target displacement. While in practice, performance limit states of multiple bridge components are evaluated to establish this target displacement, it is assumed that column reinforcement bar-buckling exclusively dictates the target displacement. While there are many empirical models in the literature that provide strain limits for bar-buckling, this paper makes use of the Feng et al. (2014a) model because it can account for the impact of the out-of-balance nature of the structural response.

The Feng et al. (2014a) model accepts two parameters as input and produces an interaction diagram between the peak compression and tension strains of longitudinal reinforcement, as shown in Fig 10a. The two input parameters are 1) 
the ratio of the longitudinal bar diameter to the transverse bar diameter $\left(d_{b l} / d_{h}\right)$ and 2) the ratio of the spiral spacing to the longitudinal bar diameter $\left(s / d_{b l}\right)$. To generate Fig 10a, bar diameters of $25 \mathrm{~mm}$ and $9.5 \mathrm{~mm}$ were chosen for longitudinal and transverse reinforcement, respectively. Also, a spiral spacing of $50 \mathrm{~mm}$ was used. If the ordered pair of peak compression and tension strain of a rebar under cyclic loading lies outside the shaded region, buckling has likely occurred. Thus, any value of tension strain that falls on the trilinear curve can be considered a limit, conditional on the same rebar's peak compression strain.

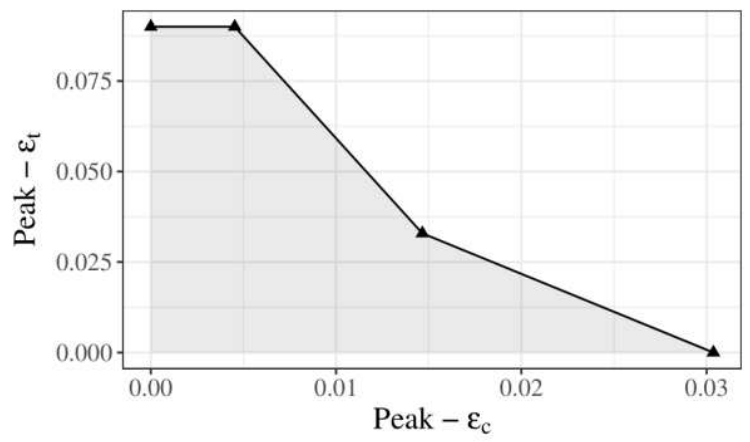

(a)

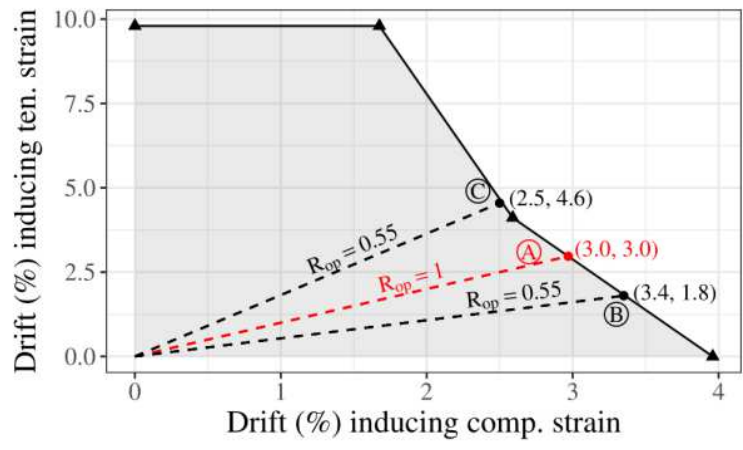

(b)

Fig 10. (a) Rebar compression to tension strain interaction envelope; (b) Interaction of strains translated into column drifts on either side of initial position.

For design, these strain limits must be converted into corresponding displacement limits. Often, bridge engineers start with a trial section for the columns and then modify them as needed. A moment-curvature or pushover analysis can be implemented to convert the strain limits to displacement or drift limits if the trial section is known. Consider a round RC column section with a diameter of $460 \mathrm{~mm}$, ten numbers of $25 \mathrm{~mm}$ diameter longitudinal rebars, and 9.5 $\mathrm{mm}$ diameter spiral reinforcement spaced at $50 \mathrm{~mm}$. A monotonic pushover analysis on a fiber-based model provided the column drifts corresponding to each strain value in Fig 10a. In this way, the Feng et al. (2014a) model can alternately be displayed in terms of peak column drift to either side of the initial position, as shown in Fig 10b. The target drift for performing DDBD can subsequently be gleaned from this figure. In their paper, Feng et al. (2014a) recommend the conservative assumption of equal peak drift to both sides of the column, i.e., $R_{o p}=1$, for a ground motion input. This assumption would mean that the drift limit must be equal to the value at point A, in Fig 10b, i.e., $3 \%$.

However, as discussed earlier, $R_{o p}$ is seldom equal to 1 under inelastic response. From Fig 7, it was observed that the median value of $R_{o p}$ for structures exhibiting response according to the modified Takeda model is 0.55 . Thus, to efficiently use the Feng et al. (2014a) model, one must also account for the expected $R_{o p}$ at any given site. To design the columns in this scenario, the two drift limit ordered pairs corresponding to an $R_{o p}$ of 0.55 are shown by points $\mathrm{B}$ and $\mathrm{C}$ in Fig 10b. The target drift can be evaluated as the smaller of the maximum drift in each ordered pair. In Fig $10 \mathrm{~b}$, the maximum drifts at point $\mathrm{B}$ and $\mathrm{C}$ are $3.4 \%$ and $4.6 \%$, respectively. Therefore, for these columns, the target drift for the bar-buckling limit state is the smaller value of 3.6\%. Notice that this new target drift is larger than the 3\% obtained by assuming an $R_{o p}$ of 1 . Designing for a larger target drift almost always results in a cheaper structure. Thus, possessing information about the expected level of $R_{o p}$ could lead to economic savings. With some additional future work, the utility of $R_{o p}$ can be further enhanced. The following section illustrates this.

\section{Future Work and Potential Implications in PBSD}

Departments of transportations (DOT) of states that fall in seismic regions often perform risk analyses of existing bridges in their inventory. A key aspect of risk analysis is the use of fragility functions that provide probabilities of 
exceedance of important limit states, given the location and structural characteristics of each bridge. For RC bridges such as the sample bridge shown in Fig 9, bar-buckling and exceeding a stipulated level for residual drift are important limit states because expensive interventions are required following these events. Although no models currently exist that can provide probabilistic relationships between $R_{o p}$ and these limit states, it is shown by the following case studies that these models can be established with future research.

Two case studies are presented to illustrate how $R_{o p}$ can become useful in estimating the likelihood of observing important structural limit states. The first case study explores the relationship between $R_{o p}$ and bar-buckling, while the second inspects the correlation between $R_{o p}$ and residual drift. For both case studies, non-linear time history (NLTH) analyses were performed on multiple SDOF RC bridge columns. The objective was to induce reinforcement bar-buckling and residual drifts in these numerical models by subjecting them to several earthquake ground motions and analyzing the results to show the impact of $R_{o p}$ on the attainment of these limit-states.

Four different RC columns were designed using DDBD principles. All four of them were designed to a conventional seismic design spectrum generated by using $S_{D S}$ and $S_{D 1}$ values obtained from ASCE-7 (2017) for a city in a high seismic region of the United States. DDBD allows for designing these columns to any desired ductility level. Therefore, it was possible to design four columns that underwent responses at four different maximum ductilities for the same hazard. The columns were designed for displacement ductilities 3, 4, 5, and 6, details of which are provided in Table 3. This approach was necessary to capture a good range of residual drift values and cases of bar-buckling. Ductilities 1 and 2 were avoided because these limit states do not occur at small ductility levels.

Table 3. Four RC column sections representing four ductility levels used in this study.

\begin{tabular}{|c|c|c|c|c|}
\hline Detail & Ductility 3 & Ductility 4 & Ductility 5 & Ductility 6 \\
\hline Section dia. (mm) & 1000 & 1000 & 1000 & 1000 \\
\hline No. of long. bars & 30 & 30 & 20 & 18 \\
\hline Dia. Of long. bars (mm) & 33 & 25.4 & 28.4 & 25.4 \\
\hline Dia. Of stirrups (mm) & 10 & 10 & 10 & 10 \\
\hline Spacing of stirrups $(\mathrm{mm})$ & 75 & 75 & 75 & 75 \\
\hline Column height $(\mathrm{m})$ & 8 & 8 & 7 & 7 \\
\hline$f_{c}^{\prime}(\mathrm{MPa})$ & 35 & 35 & 35 & 35 \\
\hline$f_{y}(\mathrm{MPa})$ & 415 & 415 & 415 & 415 \\
\hline
\end{tabular}

Dynamic analyses of RC columns were performed using the OpenSees (McKenna, 2011) platform. The columns were modeled as non-linear force-based elements with distributed plasticity and fiber sections. Each column was a single element with five integration points, as shown in Fig 11. The columns were slender, and therefore, shear deformation was not accounted for explicitly. The material models for concrete and steel reinforcement were Concrete01 and Steel02, respectively. For the section core, the Mander et al. (1988) model for confined concrete was used. Because fiber models can account for hysteretic damping through non-linear material stress-strain models, only a small $2 \%$ viscous damping was defined. Furthermore, the tangent stiffness proportional Rayleigh model was implemented by setting the mass proportional coefficient to zero. A constant column axial load ratio of 5\% was used throughout the study and P-Delta effects were accounted for using geometric transformation.

The ground motions used for NLTH analyses were downloaded from the PEER NGA-West2 database (Ancheta et al., 2014) and spectrally matched to the target design spectrum using the software Seismomatch (Seismosoft, 2013). There were seventy-five uni-directional acceleration records from multiple large magnitude events. Fig 12 shows the matched spectra for all of the ground motions alongside the target spectrum. The time interval of ground motion records was 0.005 seconds, which was also used as the time step in the Newmark integration scheme. The convergence criteria utilized was the energy increment condition available in OpenSees, which specifies a tolerance on the inner product of the unbalanced load and displacement increments at the current iteration. While the total duration of the ground motions varied among all seventy-five records, a total analysis time of 100 seconds was 
assigned to each input ground motion. Because individual durations of each record were well below 100 seconds, this enabled sufficient zero padding to obtain meaningful residual displacements.

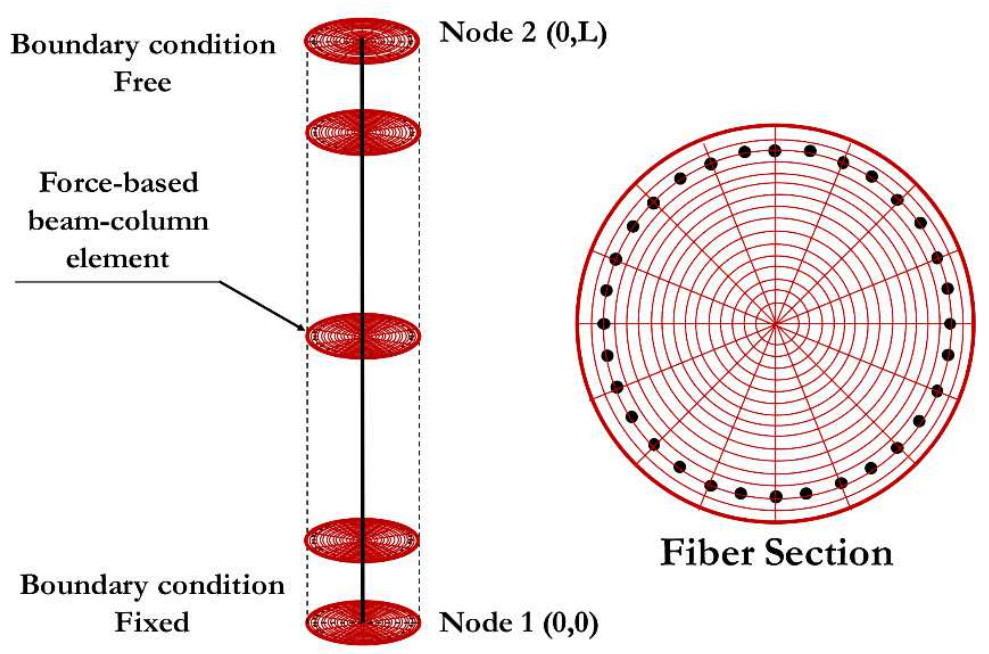

Fig 11. A model layout of the OpenSees fiber model.

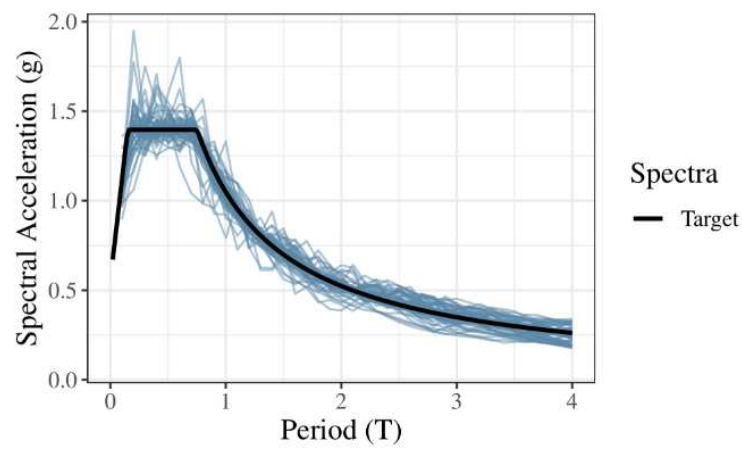

(a)

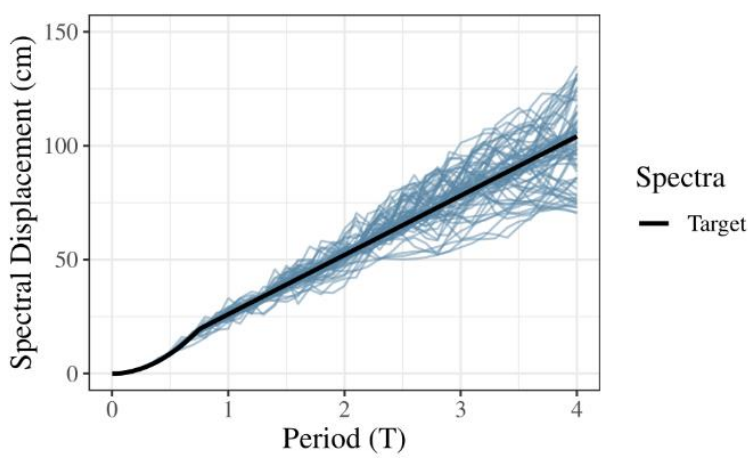

(b)

Fig 12. Response spectra of all of the matched ground motions used for non-linear time history analysis alongside the target spectrum: (a) Pseudo-acceleration; (b) Displacement.

Following the NLTH analyses of all four columns, a dataset was assembled by post-processing the relative displacements and reinforcement strain histories. This dataset was later analyzed for correlations between $R_{o p}$ and the limit-states of residual drift and reinforcement bar-buckling, as discussed in the following subsections.

\subsection{Case Study I: Longitudinal Bar-Buckling in RC Columns}

From the analysis results of RC columns, the inelastic strain histories of extreme reinforcement bars of all four columns were post-processed to determine whether they underwent buckling. The Feng et al. (2014a) bar-buckling model was used to test for buckling. Peak tension and compression strains in extreme reinforcement bars were plot as ordered pairs and checked if the point fell above or below the buckling envelope. Fig 13 shows two groups of data-points where each point represents one analysis and its corresponding peak compression and tension strains observed on the most critical extreme reinforcement bar. The blue circles denote analyses that did not exhibit bar-buckling. At the 
same time, the red crosses represent analyses that showed buckling in at least one of the longitudinal bars in the column.

The approach was to explore the relationship between $R_{o p}$ for each response and the occurrence of the bar-buckling limit state. It is intuitively obvious and has been validated by numerous studies that the peak displacement of RC columns is a significant predictor of bar-buckling. Hence, it was necessary to group the results into sets in which all of the responses underwent the same peak displacement, because only then can the relationship between $R_{o p}$ and barbuckling be isolated. In other words, the question was the following. Given the same peak displacement, can the variation in $R_{o p}$ explain the likelihood of observing bar-buckling?

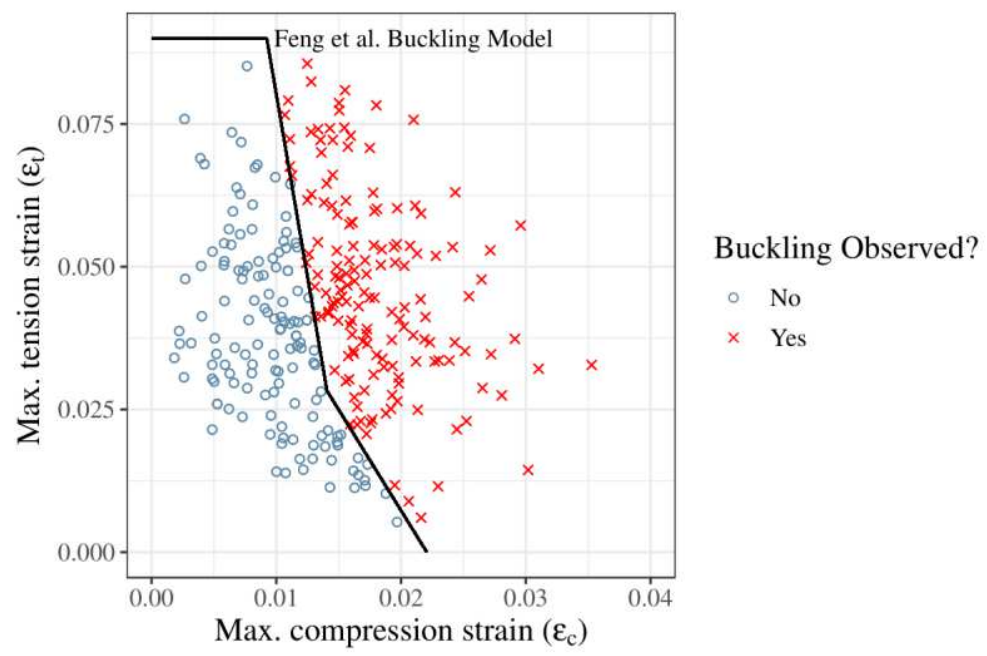

Fig 13. Results of all non-linear time history analysis regarding the status of reinforcement bar-buckling according to Feng et al. (2014a) model.

Using DDBD to design columns that respond at desired ductility levels was a step towards achieving such a grouping of equal peak displacements. However, the design was based on a composite design spectrum. Despite carrying out spectral matching of ground motions, some variation attributable to imperfect matching and inherent ground motion randomness was expected in the peak displacements. This variation was observed when the ratio of real peak displacement to target displacement was plotted against the opposite peak ratio, as shown in Fig 14.

From the full database, only those results were extracted that had a max-to-target value equal or extremely close to 1.0. Additionally, only the results of the column designed to undergo a displacement ductility of 4 were chosen because bar-buckling is more uncertain at this ductility level than ductility 3 (unlikely), or 5 and 6 (high likelihood). Fig 15 is a plot showing the probability of observing bar-buckling with increasing $R_{o p}$ for the resulting data. This plot was generated by fitting a logistic regression curve for the categorical outcome of whether buckling was observed in an analysis or not. The outcome was given a value of 1 for "Yes" and 0 for "No". A trend exhibiting a higher likelihood of bar-buckling with an increase in the observed $R_{o p}$ can be seen. This trend means that a more balanced seismic response is more "severe" to an RC column compared to an out-of-balanced response, for the limit-state of reinforcement bar-buckling. Note that this case study is just an illustration of how an empirical model in conjunction with information regarding $R_{o p}$ can help develop a probabilistic model for bar-buckling prediction. More rigorous work must be undertaken to develop these probabilistic models for different structural systems. If studies with methods similar to the above case study were to be performed on different bridge structural types, models similar to the one in Fig 15 can be developed. These models must contain multiple variables as input, including the target ductility and bridge geometry, in addition to $R_{o p}$. These improved fragility models can play a crucial role in the risk assessment of RC bridges. 


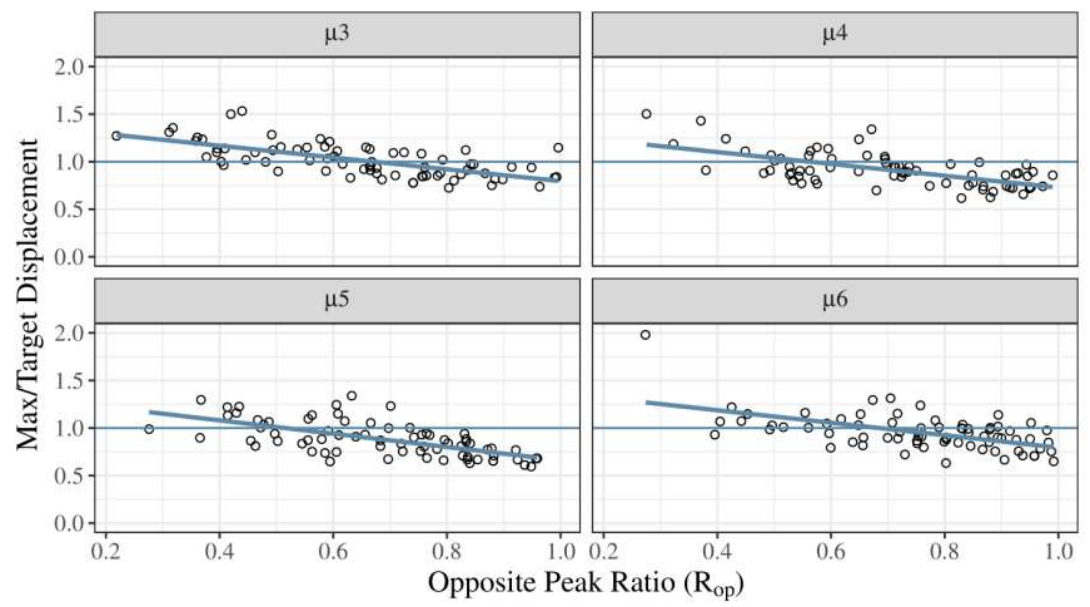

Fig 14. The ratio of maximum displacement of the non-linear response of SDOF columns as a function of design ductility and $R_{o p}$.

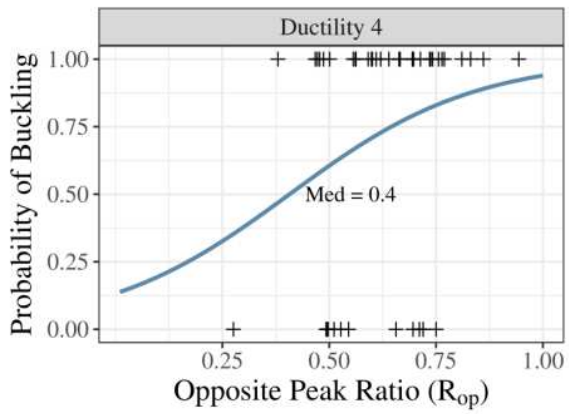

Fig 15. The probability of reinforcement bar-buckling in columns as a function of $R_{o p}$ given similar maximum displacement.

\subsection{Case Study II: Residual Drift in RC Bridge Columns}

Similar to bar-buckling, another important limit-state in RC bridges is the residual drift ratio after an earthquake. Standard highway bridges in high seismic regions such as California are typically designed so that plastic behavior concentrates in the columns during earthquakes. These columns are expected to undergo large inelastic deformations under severe earthquakes, resulting in residual displacements. Residual displacements can affect post-earthquake functionality of bridges and can determine whether a bridge remains usable following an earthquake. MacRae and Kawashima (1997); Christopoulos et al. (2003); Pampanin et al. (2003) studied the impact of multiple variables such as system strength, hysteretic rules, and source and site characteristics on residual displacements. They used simple frame elements with inelastic section hysteresis rules for their analyses. These studies observed that the residual drift for non-self-centering systems is mostly impacted by their hysteretic properties, system ductility, and P- $\Delta$ effects. Ruiz-Garcia and Miranda (2012), however, showed that residual displacements exhibited high record-to-record variability when several ground motions were considered. Erochko et al. (2010); Hamburger et al. (2012); Ruiz-Garcia and Chora (2015) have proposed approximate methods to estimate residual drift demands of buildings. But these methods use only the structure's properties as input and do not account for the variability of residual drift demands caused by ground motion characteristics. Ruiz-Garcia and Miranda (2006), and Uma et al. (2010) have proposed probabilistic approaches to estimate residual drift demands during the performance-based assessment of multi-story buildings. In these studies, residual drift was considered as the engineering demand parameter (EDP). They estimated 
the probability of exceeding this EDP given different intensity measures (IMs), such as the pseudo-spectral acceleration at the fundamental period $\left(S_{a}\left(T_{1}\right)\right)$, and the maximum inelastic displacement demand of an equivalent SDOF system having the same initial lateral stiffness $\left(\Delta_{i}\left(T_{1}\right)\right)$. While using these IMs provide useful models for residual drift estimation, the opposite peak ratio $\left(R_{o p}\right)$, as discussed next, shows better correlation with residual drift.

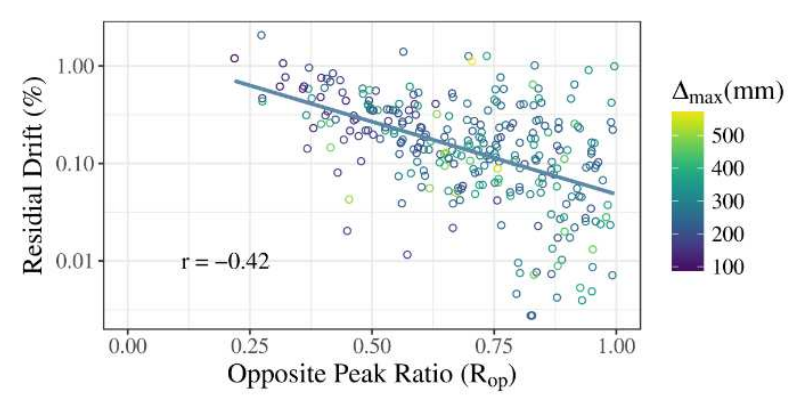

(a)

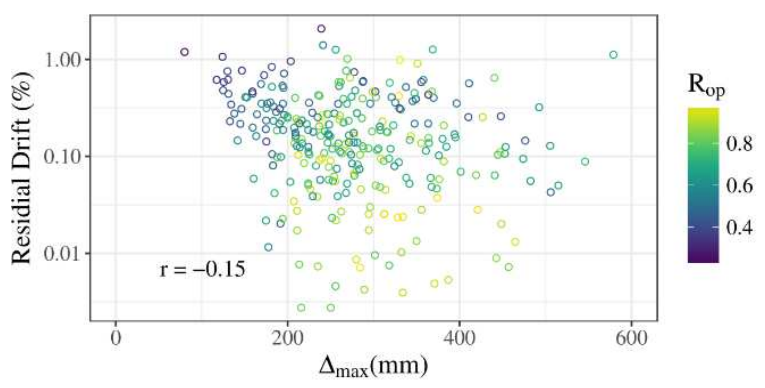

(b)

Fig 16. Correlation between (a) residual drift and $R_{o p}$, and (b) residual drift and maximum displacement of non-linear SDOF fiber models.

In this second case study, the correlation between column residual drift and $R_{o p}$ is explored. After the NLTH analyses of four SDOF columns using 75 ground motions, the residual displacement $\left(\Delta_{r e s}\right)$ of each analysis were evaluated from the corresponding response history. The residual drift ratio $\left(\Phi_{\text {res }}\right)$ for each analysis was then calculated according to Equation 5, where $L_{c}$ is the clear height of the RC column. Fig 16a shows the plot of the residual drift ratio versus $R_{o p}$ for all of the four SDOF structures, designed for different ductility levels. Pearson's correlation coefficients between $\Phi_{r e s}$ and $R_{o p}$ are also shown in the figure. There is a negative correlation between $\Phi_{r e s}$ and $R_{o p}$. This observation means that if a structure undergoes large out-of-balance response under an earthquake, its residual drift ratio will likely be larger than if the structural response was balanced. It was also observed that even for the same peak displacement, there is variation in the residual drift ratios of structures, and this variation could partly be explained by $R_{\text {op }}$.

$$
\Phi_{\text {res }}=\frac{\Delta_{\text {res }}}{L_{c}}
$$

Fig 16b shows the plot of residual drift ratios versus peak displacement for all of the structures. In this plot, there does not seem to be a correlation between the two variables. This result is counter-intuitive because one may expect more significant residual drifts associated with higher peak displacement. The above results indicate that $R_{o p}$ may be a better demand parameter compared to peak displacement for the prediction of residual drift in performance-based seismic design.

A model, such as the one proposed in this paper, that could estimate a lower bound of $R_{o p}$, can enable an engineer to account for the residual drift ratio in a risk assessment framework. Depending on the structure's importance, decisions can be made regarding unique retrofitting details to reduce the economic loss due to residual drifts.

Consider three residual drift limit states of the column exhibiting residual drifts of a) $0.1 \%, b$ ) $0.5 \%$, and c) $1.0 \%$. The results of the RC column NLTH analyses can also be characterized as whether these three limit states were achieved. Similar to the bar-buckling limit state, discussed earlier, fragility curves can be developed to provide the probability of exceeding these residual drift limits given a value of $R_{o p}$, as shown in Fig 17. Note that the $\mathrm{x}$-axis contains the inverse of $R_{o p}$ because residual drift is inversely proportional to $R_{o p}$. From the three logistic fragility curves, the probability of exceeding different residual drift $\left(\Phi_{\text {res }}\right)$ demands can be evaluated. Please note that the fragility curves in Fig 17 are only placeholders for illustration. A more in-depth investigation into the behavior of different bridge types must be performed to generate valid probabilistic models. It is worth mentioning that the usefulness of $R_{o p}$ may not be limited to only the two limit-states considered in this study. As more local damage phenomena are explained 
and characterized as performance limit-states, it must be expected that ground motion loading history will have an impact on these models on some level.

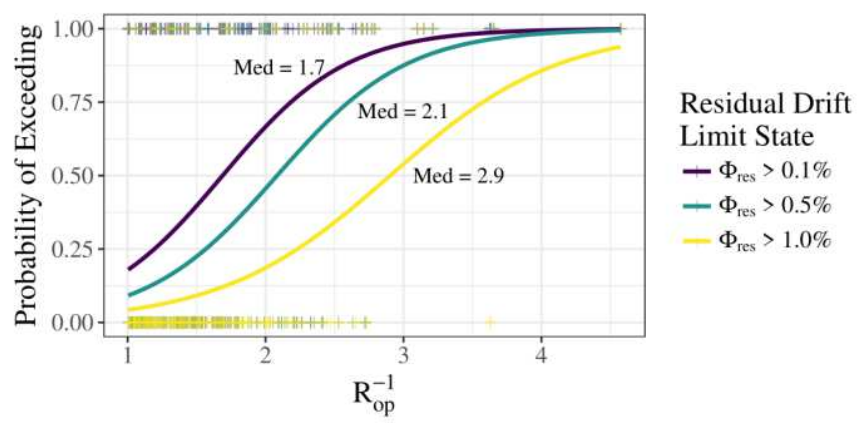

Fig 17. A placeholder fragility model for residual drift limits.

\section{Conclusions}

In this paper, a new parameter, termed as the opposite peak ratio $\left(R_{o p}\right)$, was proposed to characterize a significant aspect of seismic loading history. $R_{o p}$ quantifies the unequal displacement responses on either side of the initial position of structures. While $R_{o p}$ is an addition to the list of existing parameters that attempt to characterize seismic loading history, it is the first of this kind that has been developed from the perspective of displacement-based design. In this study, the authors developed empirical models that can estimate the $R_{o p}$ for a given set of structural parameters. Furthermore, the implications of successfully estimating $R_{o p}$ in the frameworks of displacement-based design and performance-based risk assessment was discussed.

First, a large database of past ground motion records from shallow crustal earthquakes was assembled to perform statistical analyses. These analyses led to the development of two empirical models for estimating $R_{o p}$. The first model, described by Equation 3, can be used to estimate $R_{o p}$ if the expected structural response is elastic. Similarly, the second model, described by Equation 4, estimates $R_{o p}$ for inelastic or non-linear structural response.

An application where $R_{o p}$ is immediately useful is the displacement-based seismic design of RC bridge columns for the reinforcement bar-buckling limit state. It has previously been shown that the design model is sensitive to the outof-balance nature of the structural response to ground motions. By forecasting the expected value of $R_{o p}$ at any given site, it is now possible to minimize the conservatism implicit in the current design approach. The resulting columns will be optimally designed, thereby reducing the structural cost associated with the bridge.

Case studies were conducted to illustrate the potential implications of $R_{o p}$ in the performance-based risk assessment framework. Two important limit-states were chosen, and the relationship between these and $R_{o p}$ was explored. These limit-states were the residual drift and longitudinal bar-buckling in reinforced concrete columns. It was established that variation in $R_{o p}$ could explain the likelihood of achieving these limit-states.

\section{Declarations}

\section{Funding}

Not applicable

\section{Conflicts of interest/Competing interests}

The authors declare that there are no conflicts of interest.

\section{Availability of data and material}

All data used in this manuscript will be available upon request. 


\section{Code availability}

Not applicable

\section{References}

Ancheta, T., Darragh, R., Stewart, J., Seyhan, E., Silva, W., Chiou, B.J., Wooddell, K., Graves, R., Kottke, A., Boore, D., \& others (2014). NGA-West2 database. Earthquake Spectra, 30(3), 989-1005.

ASCE-7 (2017). Minimum Design Loads and Associated Criteria for Buildings and Other Structures. American Society of Civil Engineers.

Bazaez, R., \& Dusicka, P. (2016). Cyclic loading for RC bridge columns considering subduction megathrust earthquakes. Journal of Bridge Engineering, 21(5), 04016009.

Bolt, B. (1973). Duration of strong ground motion. In Proceedings of the 5th World Conference on Earthquake Engineering (pp. 1304-1313).

Bommer, J., Hancock, J., \& Alarc'on, J. (2006). Correlations between duration and number of effective cycles of earthquake ground motion. Soil Dynamics and Earthquake Engineering, 26(1), 1-13.

Carr, A. (2008). RUAUMOKO-Inelastic dynamic analysis program. Department of Civil Engineering, University of Canterbury, Christchurch, New Zealand.

Chandramohan, R., Baker, J., \& Deierlein, G. (2016). Quantifying the influence of ground motion duration on structural collapse capacity using spectrally equivalent records. Earthquake Spectra, 32(2), 927-950.

Christopoulos, C., Pampanin, S., \& Nigel Priestley, M. J. (2003). Performance-based seismic response of frame structures including residual deformations part I: single-degree of freedom systems. Journal of Earthquake Engineering, 7(01), 97-118.

Du, W., \& Wang, G. (2017). Empirical correlations between the effective number of cycles and other intensity measures of ground motions. Soil Dynamics and Earthquake Engineering, 102, 65-74.

Erochko, J., Christopoulos, C., Tremblay, R., \& Choi, H. (2011). Residual drift response of SMRFs and BRB frames in steel buildings designed according to ASCE 7-05. Journal of Structural Engineering, 137(5), 589-599.

Fajfar, P. (1992). Equivalent ductility factors, taking into account low-cycle fatigue. Earthquake Engineering \& Structural Dynamics, 21(10), 837-848.

Fajfar, P., \& Vidic, T. (1994). Consistent inelastic design spectra: hysteretic and input energy. Earthquake Engineering \& Structural Dynamics, 23(5), 523-537.

Feng, Y., Kowalsky, M. J., \& Nau, J. M. (2015). Effect of seismic load history on deformation limit states for longitudinal bar buckling in RC circular columns. Journal of Structural Engineering, 141(8), 04014187.

Feng, Y., Kowalsky, M. J., \& Nau, J. M. (2015). Finite-element method to predict reinforcing bar buckling in RC structures. Journal of Structural Engineering, 141(5), 04014147.

Friedman, J., Hastie, T., \& Tibshirani, R. (2001). The elements of statistical learning. (Vol. 1) Springer series in statistics New York.

Goodnight, J. C., Kowalsky, M. J., \& Nau, J. M. (2013). Effect of load history on performance limit states of circular bridge columns. Journal of Bridge Engineering, 18(12), 1383-1396.

Goodnight, J. C., Kowalsky, M. J., \& Nau, J. M. (2016). Strain limit states for circular RC bridge columns. Earthquake Spectra, 32(3), 1627-1652.

Hamburger, R. O., Rojahn, C., Heintz, J., \& Mahoney, M. G. (2012, September). FEMA P58: Next-generation building seismic performance assessment methodology. In 15th world conference on earthquake engineering (Vol. 10, No. 10). 
Hancock, J., \& Bommer, J. J. (2007). Using spectral matched records to explore the influence of strong-motion duration on inelastic structural response. Soil Dynamics and Earthquake Engineering, 27(4), 291-299.

Housner, G. W. (1965, January). Intensity of earthquake ground shaking near the causative fault. In Proc. of 3rd World Conference on Earthquake Engineering (pp. 94-115).

Humar, J. (2012). Dynamics of structures. CRC press.

Husid, R. (1967). Gravity effects on the earthquake response of yielding structures (Doctoral dissertation, California Institute of Technology).

Iervolino, I., Manfredi, G., \& Cosenza, E. (2006). Ground motion duration effects on nonlinear seismic response. Earthquake engineering \& structural dynamics, 35(1), 21-38.

Jayaprakash, A., \& Kowalsky, M. (2019). Mean Balance Ratio to Characterize Ground Motion Loading History for Performance Based Design. In 12th Canadian Conference on Earthquake Engineering.

Kalkan, E., \& Kunnath, S. K. (2006). Effects of fling step and forward directivity on seismic response of buildings. Earthquake spectra, 22(2), 367-390.

Kalkan, E., \& Kunnath, S. K. (2007). Effective cyclic energy as a measure of seismic demand. Journal of Earthquake Engineering, 11(5), 725-751.

Kunnath, S. K., \& Chai, Y. H. (2004). Cumulative damage-based inelastic cyclic demand spectrum. Earthquake engineering \& structural dynamics, 33(4), 499-520.

MacRae, G. A., \& Kawashima, K. (1997). Post-earthquake residual displacements of bilinear oscillators. Earthquake engineering \& structural dynamics, 26(7), 701-716.

Malhotra, P. K. (2002). Cyclic-demand spectrum. Earthquake engineering \& structural dynamics, 31(7), 1441-1457.

Mander, J. B., Priestley, M. J., \& Park, R. (1988). Theoretical stress-strain model for confined concrete. Journal of structural engineering, 114(8), 1804-1826.

McKenna, F. (2011). OpenSees: a framework for earthquake engineering simulation. Computing in Science \& Engineering, 13(4), 58-66.

Moehle, J., \& Deierlein, G. G. (2004, August). A framework methodology for performance-based earthquake engineering. In 13th world conference on earthquake engineering (Vol. 679).

Moyer, M. J., \& Kowalsky, M. J. (2003). Influence of tension strain on buckling of reinforcement in concrete columns. ACI Structural journal, 100(1), 75-85.

Otani, S. (1980). Nonlinear dynamic analysis of reinforced concrete building structures. Canadian Journal of Civil Engineering, 7(2), 333-344.

Pampanin, S., Christopoulos, C., \& Nigel Priestley, M. J. (2003). Performance-based seismic response of frame structures including residual deformations part II: multi-degree of freedom systems. Journal of Earthquake Engineering, 7(01), 119-147.

Pan, Y., Ventura, C. E., \& Liam Finn, W. D. (2018). Effects of ground motion duration on the seismic performance and collapse rate of light-frame wood houses. Journal of Structural Engineering, 144(8), 04018112.

Priestley, M. J. N., Calvi, G. M., \& Kowalsky, M. J. (2007). Direct displacement-based seismic design of structures. In 5th NZSEE Conference (p. 11). Pavia, Italy: IUSS Press.

Pujol, S., Sozen, M. A., \& Ramirez, J. A. (2006). Displacement history effects on drift capacity of reinforced concrete columns. ACI Materials Journal, 103(2), 253.

Raghunandan, M., \& Liel, A. B. (2013). Effect of ground motion duration on earthquake-induced structural collapse. Structural Safety, 41, 119-133. 
Ramberg, W., \& Osgood, W. R. (1943). Description of stress-strain curves by three parameters.

Ruiz-García, J., \& Chora, C. (2015). Evaluation of approximate methods to estimate residual drift demands in steel framed buildings. Earthquake Engineering \& Structural Dynamics, 44(15), 2837-2854.

Ruiz-García, J., \& Miranda, E. (2006). Residual displacement ratios for assessment of existing structures. Earthquake engineering \& structural dynamics, 35(3), 315-336.

Seismosoft (2013). Seismomatch v2. 1-A computer program for spectrum matching of earthquake records

Sharpe, R. D. (1974). The seismic response of inelastic structures.

Syntzirma, D. V., Pantazopoulou, S. J., \& Aschheim, M. (2010). Load-history effects on deformation capacity of flexural members limited by bar buckling. Journal of structural engineering, 136(1), 1-11.

Teran-Gilmore, A., \& Jirsa, J. O. (2005). A damage model for practical seismic design that accounts for low cycle fatigue. Earthquake spectra, 21(3), 803-832.

Trifunac, M. D., \& Brady, A. G. (1975). A study on the duration of strong earthquake ground motion. Bulletin of the Seismological Society of America, 65(3), 581-626.

Uma, S. R., Pampanin, S., \& Christopoulos, C. (2010). Development of probabilistic framework for performancebased seismic assessment of structures considering residual deformations. Journal of Earthquake Engineering, 14(7), 1092-1111. 


\section{Figures}

\section{Figure 1}

Sample displacement response history of a non-linear SDOF oscillator with positive and negative peaks annotated.

\section{Figure 2}

Moment magnitude versus epicentral distance for the two GM datasets used in this study.

\section{Figure 3}

A schematic visualizing typical steps of bootstrapping a probability distribution for a parameter.

\section{Figure 4}

Bootstrapped mean values of elastic Rop for ground motions recorded at locations less than $40 \mathrm{~km}$ from the epicenter alongside the fitted models for the mean (solid) and its 95th-percentile two-sided confidence interval (dashed). 


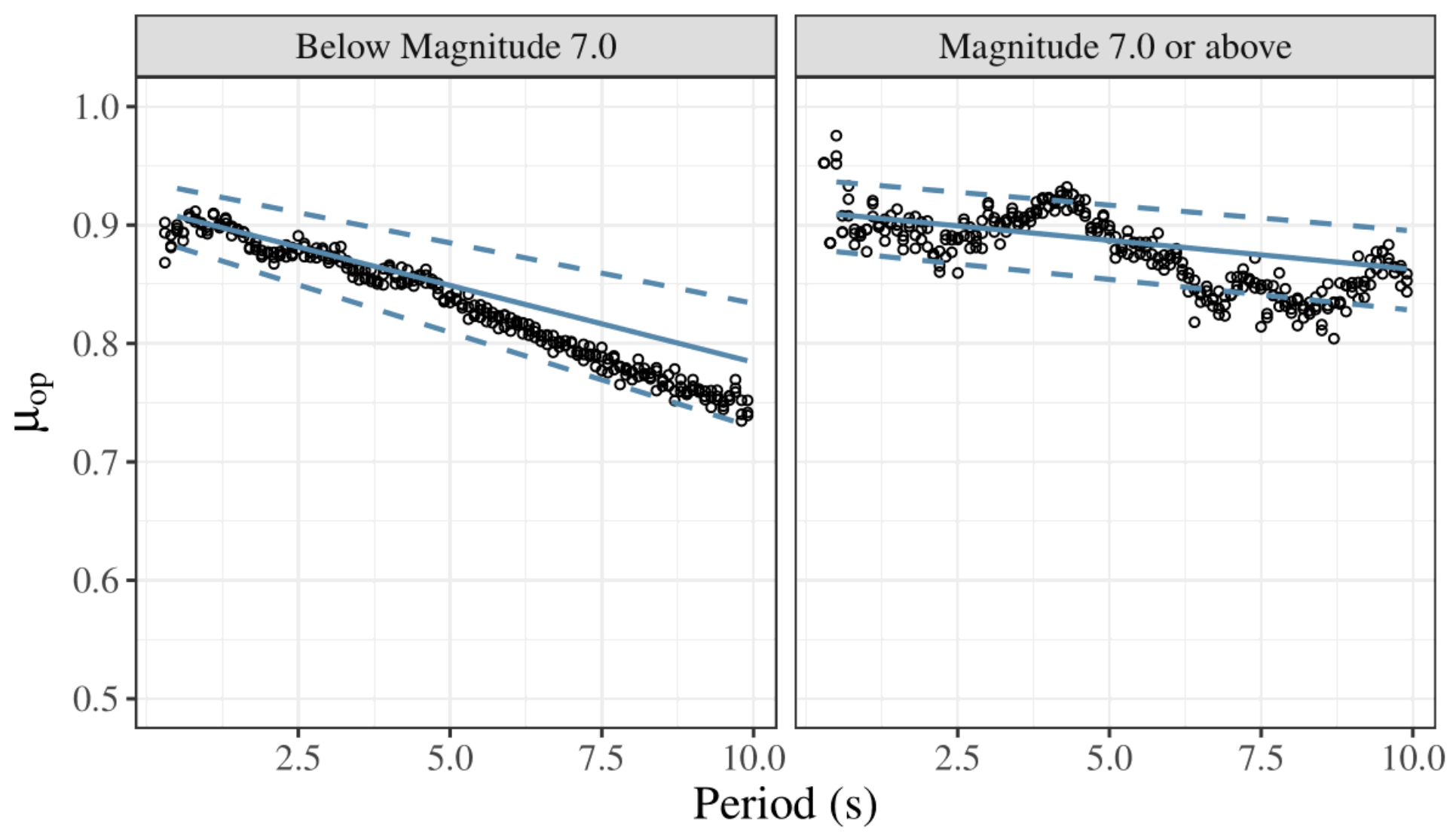

Figure 5

Mean opposite peak ratios ( $\mu \mathrm{op}$ ) for near-fault records from 500 random samples of size 2000 obtained from the validation database alongside the fitted models for the mean (solid) and its 95th-percentile twosided confidence interval (dashed).

Figure 6

Typical force-displacement cycles for the section hysteresis models used for non-linear time history analysis of SDOF systems to obtain Rop.

Figure 7

shows boxplots of observed Rop values for each hysteretic model. 


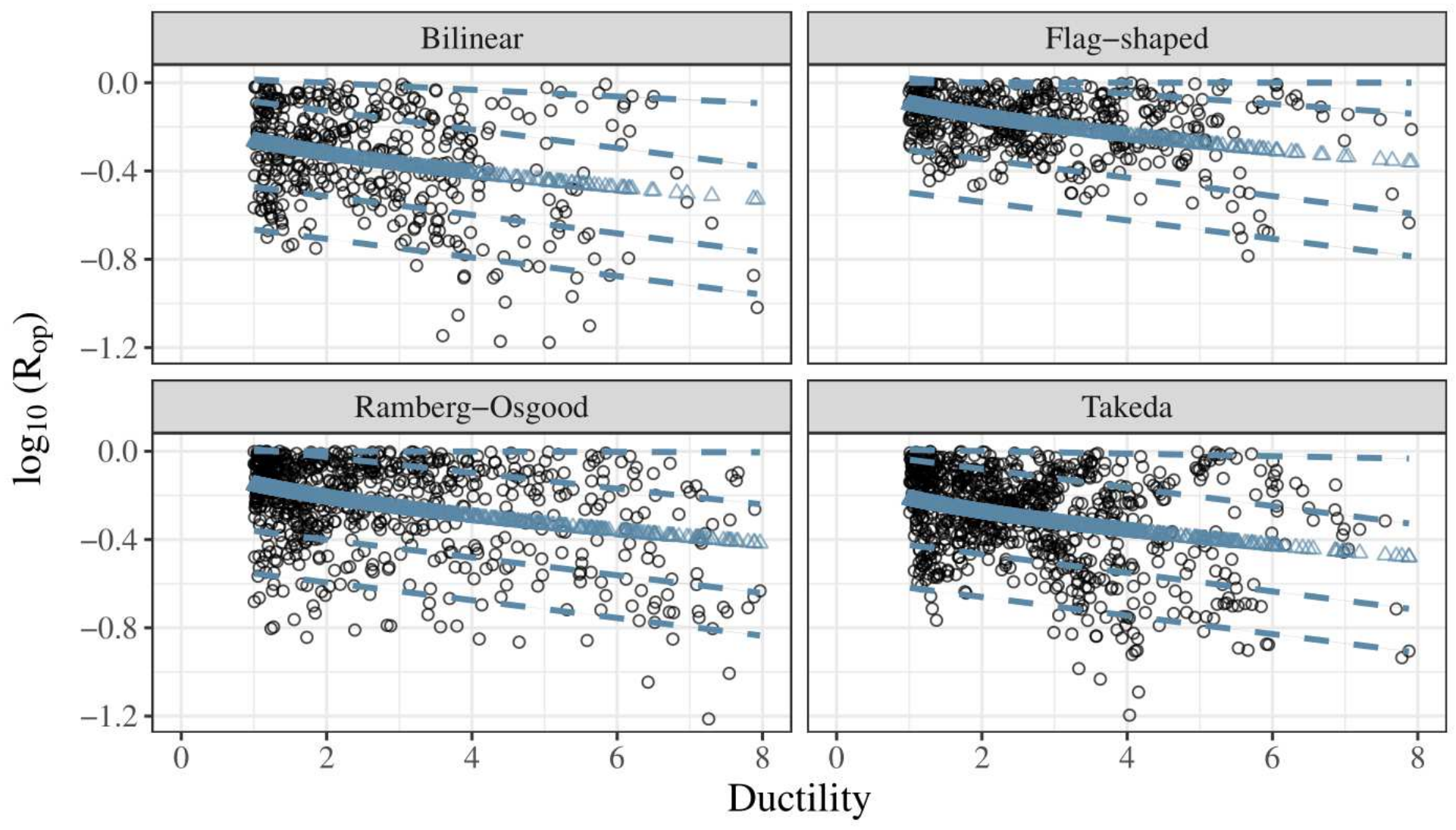

Figure 8

Non-linear log10 (Rop) plotted against the SDOF ductility for each hysteretic model.

Figure 9

A sample bridge structure.
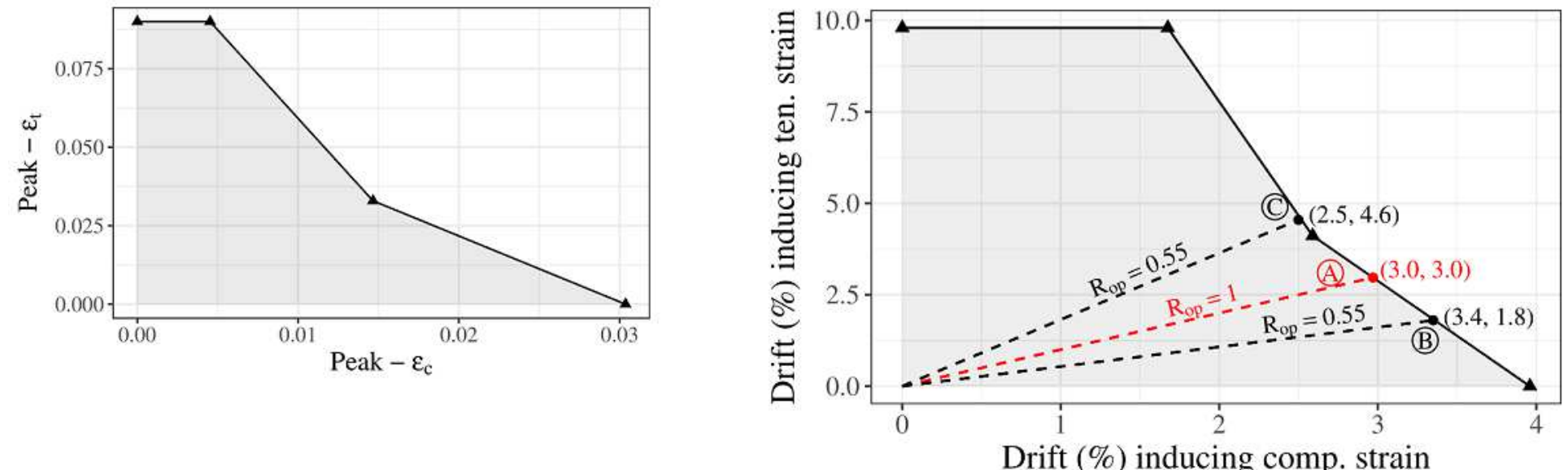

Figure 10 
(a) Rebar compression to tension strain interaction envelope; (b) Interaction of strains translated into column drifts on either side of initial position.

\section{Figure 11}

A model layout of the OpenSees fiber model.
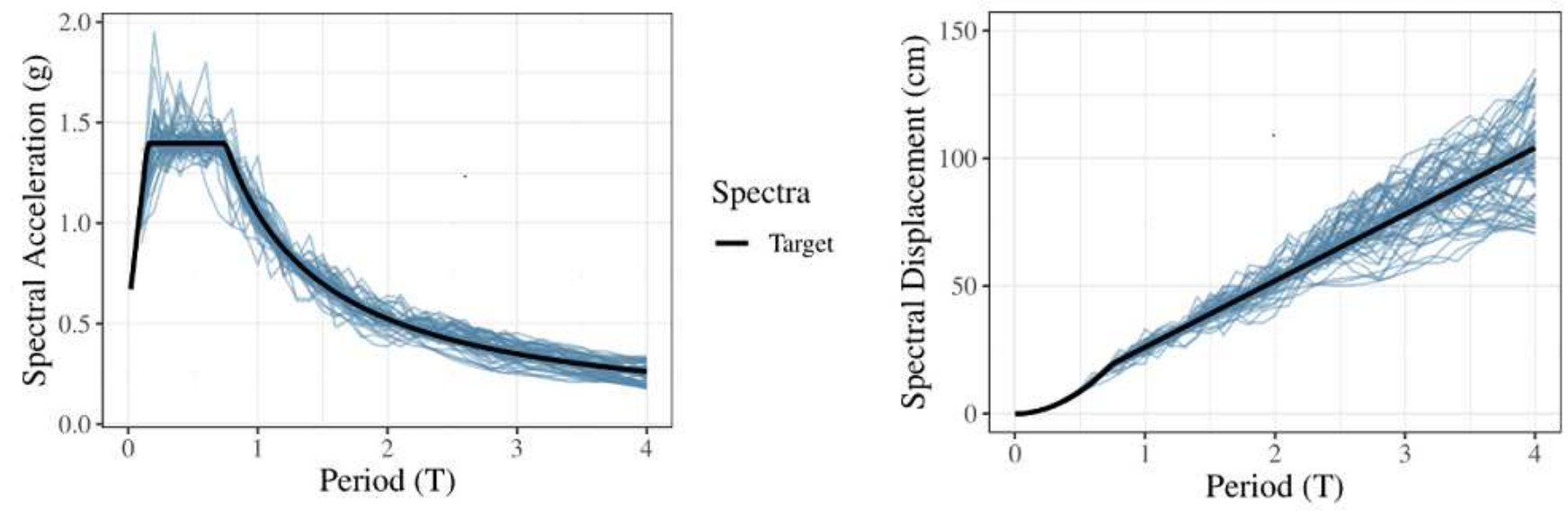

Figure 12

Response spectra of all of the matched ground motions used for non-linear time history analysis alongside the target spectrum: (a) Pseudo-acceleration; (b) Displacement.

Figure 13

Results of all non-linear time history analysis regarding the status of reinforcement bar-buckling according to Feng et al. (2014a) model. 


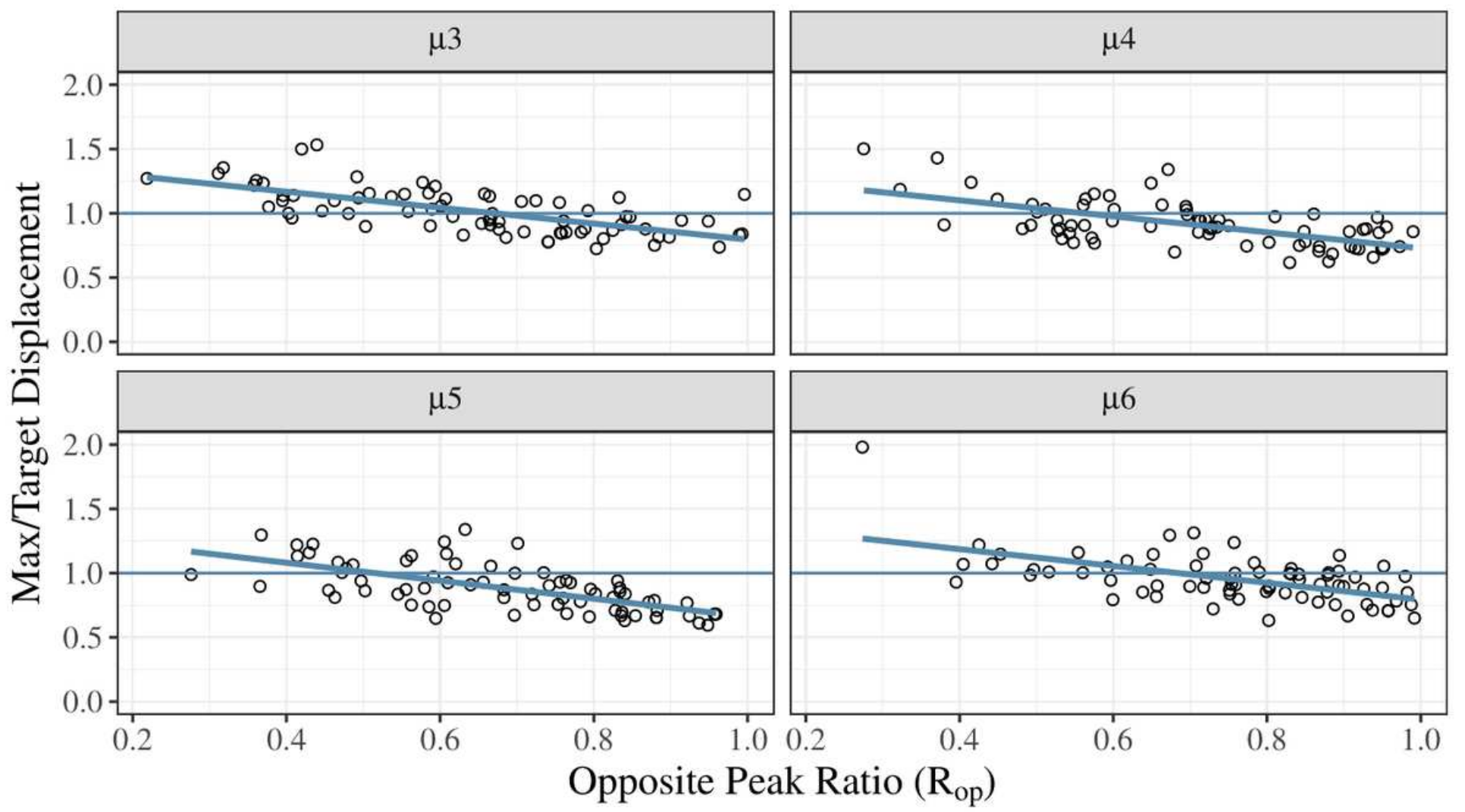

Figure 14

The ratio of maximum displacement of the non-linear response of SDOF columns as a function of design ductility and R_op.

\section{Figure 15}

The probability of reinforcement bar-buckling in columns as a function of R_op given similar maximum displacement

Figure 16

Correlation between (a) residual drift and Rop, and (b) residual drift and maximum displacement of nonlinear SDOF fiber models.

\section{Figure 17}

A placeholder fragility model for residual drift limits. 